\title{
Low-Temperature Nitriding of Deformed Austenitic Stainless Steels with Various Nitrogen Contents Obtained by Prior High-Temperature Solution Nitriding
}

Bottoli, Federico; Winther, Grethe; Christiansen, Thomas Lundin; Dahl, Kristian Vinter; Somers, Marcel A. J.

Published in:

Metallurgical and Materials Transactions A: Physical Metallurgy and Materials Science

Link to article, DOI:

$10.1007 / \mathrm{s} 11661-016-3559-7$

Publication date:

2016

Document Version

Peer reviewed version

Link back to DTU Orbit

Citation (APA):

Bottoli, F., Winther, G., Christiansen, T. L., Dahl, K. V., \& Somers, M. A. J. (2016). Low-Temperature Nitriding of Deformed Austenitic Stainless Steels with Various Nitrogen Contents Obtained by Prior High-Temperature Solution Nitriding. Metallurgical and Materials Transactions A: Physical Metallurgy and Materials Science, 47(8), 4146-4159. https://doi.org/10.1007/s11661-016-3559-7

\section{General rights}

Copyright and moral rights for the publications made accessible in the public portal are retained by the authors and/or other copyright owners and it is a condition of accessing publications that users recognise and abide by the legal requirements associated with these rights.

- Users may download and print one copy of any publication from the public portal for the purpose of private study or research.

- You may not further distribute the material or use it for any profit-making activity or commercial gain

- You may freely distribute the URL identifying the publication in the public portal 


\title{
Low-temperature nitriding of deformed austenitic stainless steels with various nitrogen contents obtained by prior high temperature solution nitriding
}

\author{
Federico Bottoli, Grethe Winther, Thomas L. Christiansen, \\ Kristian Vinter Dahl, Marcel A.J. Somers
}

Technical University of Denmark, Department of Mechanical Engineering, Produktionstorvet b.425, 2800

Kgs. Lyngby, Denmark

E-mail: febot@mek.dtu.dk, grwi@mek.dtu.dk, tch@mek.dtu.dk, kvd@mek.dtu.dk, somers@mek.dtu.dk

Phone: +4545252250

Corresponding author: Marcel A.J. Somers, somers@mek.dtu.dk

Phone: +4545252250

Fax: +4545936213

\section{Keywords}

High-nitrogen steels, high-temperature solution nitriding, low-temperature nitriding, nitrogen, austenitic stainless steel

\section{Abstract}

In the past decades, high nitrogen steels (HNS) have been regarded as substitutes for conventional austenitic stainless steels because of their superior mechanical and corrosion properties. However, the main limitation to their wider application is their expensive production processes.

As an alternative, high temperature solution nitriding has been applied to produce HNS from three commercially available stainless steel grades (AISI 304L, AISI 316 and EN 1.4369). The nitrogen content in each steel alloy is varied and its influence on the mechanical properties and the stability of the austenite investigated. Both hardness and yield stress increase and the alloys remain ductile. In addition, strain- 
induced transformation of austenite to martensite is suppressed, which is beneficial for subsequent low temperature nitriding of the surface of deformed alloys. The combination of high and low temperature nitriding results in improved properties of both bulk and surface.

\section{Introduction}

The increasing demand for high-strength and corrosion-resistant alloys has resulted in the advent of highnitrogen steels (HNS) as a potential substitute for conventional stainless steels in various engineering applications [1]. Interstitial alloying with nitrogen offers unique advantages over dissolving interstitial elements as boron and carbon, because of the high solid solubility of nitrogen in austenite combined with an effective solid-solution strengthening effect [2-4]. Nitrogen provides a remarkable increase in yield and tensile strength, without sacrificing the toughness [4-7]. Furthermore $\mathrm{N}$ dissolved in steel is a strong austenite stabilizer, which means that lower amounts of expensive austenite formers as nickel are required and the formation of ferrite and/or martensite upon solidification or deformation can be prevented [8]. In addition to a considerable improvement of the mechanical properties, the interstitial dissolution of nitrogen in stainless steel can lead to a significant improvement of the resistance against localized corrosion as crevice and pitting corrosion as it enhances the PREN and MARC numbers importantly [9-12]. Due to the favorable combination of improved mechanical properties and corrosion performance, in the past decades HNS have become an important class of engineering materials. However, despite several advantages, the major obstacle to a wider application of this class of stainless steels is related to their production. The solubility of nitrogen in liquid $\mathrm{Fe}$ is only $0.045 \mathrm{wt} \%$ at $1600{ }^{\circ} \mathrm{C}$ [13]. Consequently, the production of HNS requires high-pressure melting technologies or the utilization of powder metallurgy techniques $[9,10]$. In contrast to the liquid state, the solubility of nitrogen is higher in the solid state [2]. Hence, rather than dissolving nitrogen in the liquid state or the synthesis of high nitrogen steel powder, gas treatment of the steel component, such as solution nitriding, followed by rapid (gas) quenching to prevent nitride formation [15,16], can be applied to dissolve nitrogen in the matrix. This process can be applied to austenitic stainless steel grades to enhance the austenite stability or to duplex and ferritic stainless steel in order to stabilize the austenitic phase at high temperature.

The excellent bulk properties that can be obtained by solution strengthening can be coupled with outstanding surface properties if the material is subsequently subjected to a low-temperature thermochemical 
treatment [17-19]. Low-temperature nitriding for instance allows the dissolution of a high amount of nitrogen (up to 38 at $\%$ ) in the surface zone, leading to the formation of a supersaturated solid solution of nitrogen in austenite. This zone has been dubbed S-phase $[17,18]$ or, preferably, expanded austenite [19]. Recent reviews on the development of low temperature surface hardening can be found in $[20,21,22]$. A historical perspective is provided in [23]. The formation of an expanded austenite case results in a significant improvement in the resistance to galling and improves pitting corrosion properties as well as a considerable increase in the wear and fatigue resistance of the component [24-30]. In the present work, high temperature solution nitriding (HTSN) and low temperature nitriding (LTN) are investigated. Both processes entail incorporation of nitrogen in solid solution in stainless steel. Different HTSN treatments were applied onto three commercial alloys (AISI 316, AISI 304L and EN. 1.4369) to study the influence of nitrogen alloying on the mechanical properties and behavior upon tensile deformation. HTSN treated materials before and after plastic deformation were subsequently low-temperature nitrided and the nitriding response was analyzed to investigate the sensitivity of the low-temperature nitriding treatment for the solution nitrided and deformed structure.

\section{Experimental}

\subsection{Materials}

The compositions of the alloys investigated in this study (AISI 316, AISI 304L and EN 1.4369) are given in Table 1. The most important differences between these three commercially available stainless steel grades are the $\mathrm{Cr}, \mathrm{Ni}$ and $\mathrm{Mn}$ contents, which influence the nitrogen solubility and the stability of the austenite phase against martensite formation during plastic straining [5].

The materials were delivered as sheets: AISI 316 and EN 1.4369 as $0.7 \mathrm{~mm}$-thick sheets and AISI 304L as $0.45 \mathrm{~mm}$-thick sheet. Microstructure analysis revealed a fully austenitic structure for all the three alloys, with hardness and grain sizes as given in Table 2. The microstructure investigations are consistent with an annealed state of the as-received sheet materials. The higher hardness in EN 1.4369 as compared to AISI 316 and AISI 304L, despite the larger grain size, is explained from the solution strengthening induced by the presence of nitrogen as an alloying element. 
Tensile test specimens in accordance with ASTM standard E 8M-04 [31] were cut from the plate material for determination of the mechanical properties and for applying pre-defined levels of tensile straining.

\subsection{High-temperature solution nitriding}

High-temperature solution nitriding treatment as applied in this work is a commercial process provided by the company Expanite A/S [32,33]. Tensile test specimens of the three selected steel grades, with the thickness as provided in section 2.1, were subjected to three different high-temperature solution nitriding treatments. The various steel grades were treated in the same batch. All grades were treated at a solution nitriding temperature of $1423 \mathrm{~K}\left(1150^{\circ} \mathrm{C}\right)$ in three batches at the $\mathrm{N}_{2}$ pressures $0.3 \mathrm{bar}(\mathrm{HTSN} 1), 0.6 \mathrm{bar}$ (not investigated in detail in this work) and 0.9 bar (HTSN2). The durations of the treatments were the same (4 hours) and resulted in samples with uniform nitrogen content throughout the sample. A high-pressure gas quench was applied to avoid the formation of nitride precipitates during cooling. The nitrogen contents in the steels after the HTSN treatment were measured with inert gas fusion thermal conductivity detection with a LECO TN500 nitrogen analyzer. Thermodynamic equilibrium calculations related to solution nitriding of the alloys were performed using Thermo-Calc version 4.1 with the Thermo-Calc TCFE7.0 database [34-36].

\subsection{Plastic deformation through tensile straining}

Tensile test specimens obtained in as-received and solution nitrided conditions were plastically deformed to different equivalent strain levels through tensile straining at a strain rate of $6.67^{*} 10^{-3} \mathrm{~s}^{-1}$. The tensile loading direction was chosen parallel to the rolling direction of the plate.

The materials were tensile strained up to the following equivalent strain levels:

- AISI 316: 0.15, 0.30, 0.42

- $\quad$ AISI 304L: 0.15, 0.30, 0.45 .

- EN 1.4369: 0.15, 0.30, 0.50 .

The difference in final equivalent strains is related to a difference in ductility among the alloys.

\subsection{Low-temperature nitriding}


Specimens with dimension $15 \times 12.5 \mathrm{~mm}^{2}$ were cut from the solution nitrided tensile test specimens before and after plastic deformation. These samples were ground and polished, using a final step of $3 \mu \mathrm{m}$ diamond paste and subsequently electro-polished in order to remove the grinding-induced plastic deformation at the surface. Electro-polishing was carried out in a "Struers Polectrol" using "Struers electrolyte A2" with an applied potential of $30 \mathrm{~V}$ and a current density of $2 \mathrm{~A} / \mathrm{cm}^{2}$.

The samples were low temperature nitrided in an industrial LAC annealing furnace model PKRC 55/09 retrofitted for gaseous nitriding under gas circulation. The sample surface was activated in-situ with a proprietary treatment in order to enable the low-temperature surface hardening.

The low-temperature nitriding (LTN) process was performed for all samples at $703 \mathrm{~K}\left(430^{\circ} \mathrm{C}\right)$ for $20 \mathrm{~h}$ in a partly dissociated ammonia atmosphere. The process temperature was controlled during the entire processing, including heating, nitriding and cooling, through a type-K thermocouple placed in the proximity to the samples.

\subsection{Microstructure characterization}

The microstructure of all samples before and after plastic deformation and after low-temperature nitriding was investigated in cross-sections with reflected-light microscopy. The samples were ground, polished and etched with Kalling's reagent no. 1 for 4-8s, depending on the sample condition. Micrographs were collected using a Neophot 30 operated with a 100x oil immersion planapochromate objective for optimal resolution. A Future-tech FM700 was used for microhardness indentation; loads of $2 \mathrm{~N}$ and $0.05 \mathrm{~N}$ were applied for the assessment of the hardness in the bulk and nitrided zone respectively. The bulk hardness values presented are the average of 25 measurements.

X-ray diffractometry for phase identification was carried out with the Bragg-Brentano symmetric setting and with grazing incidence in a Bruker D8 AXS X-ray diffractometer equipped with Cr-anode and Göbel mirror in the incident beam. The step size was equal to $0.03^{\circ} 2 \theta$ and a counting time of $4 \mathrm{~s}$ per $2 \theta$ step.

Glow discharge emission spectroscopy (GD-OES) was applied for the determination of the surface composition profiles after LTN treatments. The controlled sputtering of the surface was performed with a plasma at 1000Pa and 40W using a Horiba Jobin Yvon GD profiler 2. Quantification of the concentration depth-profiles was achieved using a selection of stainless steel reference materials supplemented with a custom-made $\gamma^{\prime}-\mathrm{Fe}_{4} \mathrm{~N}$ layer on pure iron as the nitrogen reference. 


\section{Results and interpretation}

\subsection{Solution nitriding}

Calculated cross-sections in the phase diagrams, displaying the $\gamma$ phase field in the temperature range 1223$1623 \mathrm{~K}\left(950-1350^{\circ} \mathrm{C}\right)$ vs. the nitrogen content up to $0.8 \mathrm{wt} \%$ in the alloys, are shown in Fig. 1a-c together with $\mathrm{N}_{2}$ isobars that would provide the given nitrogen contents in the steels under equilibrium conditions. Clearly, in principle the nitrogen content in austenite can be adjusted by controlling the $\mathrm{N}_{2}$ pressure during high-temperature solution nitriding, provided that equilibrium is achieved between nitrogen in the gas and nitrogen dissolved in the solid state. The nitrogen contents and grain sizes after HTSN1 and HTSN2 in the three stainless steels are listed in Table 3. A comparison of nitrogen contents calculated by ThermoCalc with the experimentally determined nitrogen contents is given in Fig.1d for the three steels and all three solution nitriding treatments. For the data in Fig. 1d austenite was the only stable phase. An excellent agreement is achieved between the predicted and experimental nitrogen contents, in correspondence with earlier findings of Frisk [37].

Evidently, along with the dissolution of nitrogen in the solid state at $1423 \mathrm{~K}\left(1150^{\circ} \mathrm{C}\right)$ substantial grain growth has occurred in the three selected steels (cf. Table 2 and 3). Apparently, the actual grain growth is only determined by the combination of temperature and time, which were the same for the HTSN treatments, and not by the $\mathrm{N}_{2}$ pressure (or the dissolved nitrogen content in the sample).

\subsection{Mechanical properties}

The materials in the as-received condition and after the HTSN treatments at 0.3 bar and 0.9 bar $\mathrm{N}_{2}$ pressure were plastically deformed through tensile straining to different equivalent strain levels. The stress-strain curves obtained in uniaxial tension for the three steel grades are given in Fig. 2a. All curves for AISI 304 and EN 1.4369 are fitted excellently with the Voce equation, which gives the relation between stress, $\sigma$, and strain, $\varepsilon$.

$$
\sigma(\varepsilon)=\sigma_{y}+\sigma_{S S}\left\{1-e^{-n \varepsilon}\right\} \quad \text { for } \varepsilon>0.02
$$

where $\sigma_{y}$ and $\sigma_{S S}$ are the yield stress and the saturation stress, respectively and $n$ is the work-hardening exponent. 
The curves for AISI 316 are also well-fitted by the equation, albeit slightly poorer than for AISI 304 and EN 1.4369. Fig. $2 \mathrm{~b}$ displays the obtained Voce parameters. The dissolution of nitrogen in austenite gives a significant increase in both the yield stress and saturation stress, while the work-hardening exponent decreases. The Voce parameters for AISI 304 and EN 1.4369 are comparable, while AISI 316 has a higher $\mathrm{n}$-value than the other two alloys. Accordingly, the dissolution of nitrogen not only induces substantial strengthening of the steel, but also changes the work-hardening behaviour. As demonstrated by the insets in

Fig. 2a, nitrogen introduces a yield point phenomenon. The experimentally determined upper yield points are consistently higher than the fitted $\sigma_{\mathrm{y}}$ as shown in Fig. $2 \mathrm{~b}$ for non-vanishing nitrogen concentrations. For AISI $304 \mathrm{~L}$ and 316 the yield strength is enhanced more than $100 \mathrm{MPa}$ for HTSN1 and $150 \mathrm{MPa}$ for HTSN2. By contrast, the yield strength of EN 1.4369 after HTSN1 is comparable to the one of the as-received material, despite a considerable increase in nitrogen content (cf. Tables 1 and 3). This will be discussed below.

\subsubsection{Hardness}

The bulk hardness in the solution-nitrided samples is given as a function of the equivalent deformation in Fig. 3a. In all alloys, the bulk hardness increases with the applied plastic (tensile) strain. For the as-received condition a disproportionately large hardness increase is obtained for the first plastic deformation, while for the solution-nitrided samples the hardness increases linearly with equivalent strain. For each equivalent deformation level, and for all tested materials, higher nitrogen content results in higher bulk hardness. The increase in hardness with the applied equivalent strain is shifted toward higher hardness values as the nitrogen content in the alloy increases.

The hardness as a function of the nitrogen content for equivalent strains: $\varepsilon=0, \varepsilon=0.15$ and $\varepsilon=0.30$ is given in Fig.3b. For each steel type and for all solution nitriding treatments, a significant increase of the bulk hardness with dissolved nitrogen content is observed in Fig. 3b. The dashed lines in Fig.3b guide the eye to show that there is a clear dependence of the bulk hardness on the nitrogen content. Clearly, from Figs. 3 it also follows that the hardness increase that is achieved by plastic deformation is larger than the hardness increase obtained by interstitial alloying, irrespective of the nitrogen content.

\subsubsection{Phase stability}


X-ray diffractograms of the HTSN treated and subsequently deformed steels are given as a function of the equivalent plastic strain for HTSN1 in Fig. 4a and for HTSN2 in Fig. 4b, for the highest equivalent plastic strain applied. All diffractograms given, show that samples remained entirely austenitic on uniaxial tensile deformation. No indications for the development of b.c.c. or h.c.p. martensite were found. In our previous work it was shown that EN.14369 in the as-delivered (annealed) condition remains fully austenitic upon plastic deformation, while AISI 304, with a slightly different composition than the AISI 304L in the present investigation, develops a substantial amount of deformation-induced martensite [38]. Obviously, the stability of austenite against strain-induced martensite formation should be attributed to the presence of nitrogen in solid solution. For the present case the HTSN treated AISI 304L and AISI 316 do not develop strain-induced martensite, indicating that an effective stabilization of austenite can be achieved by introducing nitrogen in the HTSN treatment. Perhaps a lower nitrogen content than dissolved in the current experiments could suffice to prevent strain-induced martensite formation.

\subsection{Low-temperature nitriding}

Low-temperature nitriding (LTN) was performed as a finishing treatment for the three selected alloys after the HTSN treatment and plastic deformation. The nitriding responses of HTSN1 and HTSN2 for the three steels are discussed separately below.

\subsubsection{Low temperature nitriding after HTSN1}

Cross-sectional micrographs of the three alloys after low-temperature nitriding $(\mathrm{LTN})$ at $703 \mathrm{~K}\left(430^{\circ} \mathrm{C}\right)$ for 20h of HTSN1 treated steels with and without additional plastic deformation are given in Figure 5.

Irrespective of the straining conditions, in all materials the low-temperature nitriding treatment produced a nitrided zone depth of approximately $12 \mu \mathrm{m}$. The hardness of the layer was $1200 \mathrm{HV} \mathrm{V}_{0.05 \mathrm{~N}}$ throughout the case. Within experimental accuracy the thickness of the nitrided zone appears independent of the alloy composition (including the nitrogen content) and the equivalent strain. The featureless expanded austenite zone indicates a higher resistance against dissolution in the etchant, as compared to the bulk (Fig. 5), strongly suggests that no development of $\mathrm{CrN}$ has occurred by decomposition of expanded austenite (or direct nucleation in strain-induced martensite) under the applied treatment conditions. 
In previous experimental activities, it has been demonstrated that plastic deformation for similar applied equivalent strain levels has no influence on the morphology of the nitrided layer for EN 1.4369, while for AISI 304 (without nitrogen), the presence of strain-induced martensite was demonstrated to promote the precipitation of $\mathrm{CrN}$ and cause an increase of the case depth [38]. The present results confirm that a fully austenitic structure, even in the deformed condition, provides a reproducible LTN behaviour because no strain-induced martensite is present prior to low-temperature nitriding.

In the micrographs in Fig.5, two features need further explanation: i. a thin relatively bright zone close to the surface and ii. a thin white zone ahead of the expanded austenite front. These features require additional microstructure characterization.

Bragg-Brentano geometry X-ray diffractograms were collected for all the LTN treated steels at the different equivalent deformation levels ( $\varepsilon=0, \varepsilon=0.15, \varepsilon=0.30$ and $\varepsilon=$ max). Fig. 6 shows the $X$-ray diffractograms for the three steels treated according to HTSN1, at the highest equivalent strain level and after LTN. In the diffractograms three expanded austenite peaks are prominently present and the corresponding reflections of the austenite, generated from the underlying substrate, are also observed, indicating that the effective information depth of the X-rays is deeper than the case depth. In all cases, the expanded austenite peaks are characterized by asymmetric broadening to the high angle side of the peak. This effect is related to the falling nitrogen concentration over the information depth of the probing X-rays (cf. GDOES profiles in Fig. 7). The behaviour is most pronounced for the $220 \gamma$ reflection, because the information depth increases with the scattering angle $2 \theta$, and, according to Bragg's law, the lattice spacing range corresponds to a larger $2 \theta$ range 220 than for 111 and 200 reflections. No peaks related to the presence of $\mathrm{CrN}$ were found, consistent with the reflected light micrographs in Fig.5. Small intensity peaks related to the presence of $\varepsilon-(\mathrm{Fe}, \mathrm{Cr})_{2} \mathrm{~N}_{1-z}$ could be identified. Most likely this hexagonal epsilon nitride $\left(\varepsilon-(\mathrm{Fe}, \mathrm{Cr})_{2} \mathrm{~N}_{1-z}\right)$ is present at the surface and corresponds to the surface-adjacent white zone in Fig. 5a-f, where the highest nitrogen contents are present. See in this respect also the detailed characterization with grazing incidence XRD on nitrided AISI 630 [39], which shows the presence of $\varepsilon$-phase at the surface in correspondence with a high nitrogen content. GD-OES depth profiles of nitrogen and carbon for all the alloys (Fig. 7) confirm the presence of very high nitrogen contents in the surface and a carbon accumulation at the case-core transition and close to the surface. Evidently, carbon accumulates ahead of the nitrogen expanded region and reaches up to 1.4 at\% for EN 1.4369. All alloys show the same trend, and the accumulation increases with the carbon content 
originally present in the alloy (cf. Table 1). This is also reflected by an increase of the carbon accumulated with the level of carbon reached at a depth beyond the accumulation, which is clearly highest for EN 1.4369 (Fig. 7f). The occurrence of carbon accumulation underneath the nitrogen-rich zone is generally observed during nitrocarburizing of stainless steel (cf. [22,30,40-43]). In the present case, the carbon accumulation ahead of the nitrogen profile is explained from pushing ahead the carbon already present in the as-received alloys. This happens because iron and chromium atoms prefer a coordination by nitrogen atoms rather than carbon atoms, as reflected by short range ordering of $\mathrm{Cr}$ and $\mathrm{N}$ atoms in expanded austenite, while such ordering is less pronounced between $\mathrm{Cr}$ and $\mathrm{C}$ (cf. $[44,45]$ ) The carbon present in the first $2 \mu \mathrm{m}$ of the GDOES profiles (Fig. 7) could be a consequence of surface contamination that is forward sputtered during GDOES investigation, as is generally observed. However, since $\varepsilon$-phase can dissolve high quantities of carbon [46-50], the carbon close to the surface could also have been introduced in the LTN treatment, thus promoting the development of $\varepsilon$-phase in this depth range during the LTN treatment. In this respect it is striking that the depth range of the light bands at the surface of the cases observed in Figs. 5 correlates with the depth range where carbon is present.

Despite only nitriding was applied in this work, this process is highly sensitive to even minor impurity contents of carbon thus carbon absorption could have taken place because of the presence of carbon contamination in the experimental set-up.

\subsubsection{Low-temperature nitriding on HTSN2}

Reflected-light micrographs of cross sections of the steels after solution nitriding treatment HTSN2, deformation and low-temperature nitriding, are presented in Fig. 8.

In all investigated samples, the LTN treatment of the alloys after HTSN2 and plastic deformation led to the development of a surface region of expanded austenite. For all materials, the expanded austenite case appears featureless after etching, indicating a higher corrosion resistance than the substrate. Again, no significant difference in zone thickness and morphology can be observed between the investigated alloys despite the different chemical compositions of the alloys and the applied equivalent strains. Even for this nitriding condition the hardness of the case was $1200 \mathrm{HV}_{0.05 \mathrm{~N}}$.

At the outermost surface of expanded austenite, a brighter zone can be identified, which, as pointed out above, is most likely related to the presence of epsilon nitrides $\left(\varepsilon-(\mathrm{Fe}, \mathrm{Cr})_{2} \mathrm{~N}_{1-z}\right)$ (cf. section 3.3.1). 
XRD investigation in Bragg-Brentano geometry confirmed the formation of expanded austenite after the LTN treatment (Fig. 9). In the diffractograms, peaks both of expanded austenite and the underlying austenite substrate can be observed. For all materials, even at the highest applied tensile strain, no evidence for the presence of $\mathrm{CrN}$ was identified. However, as for HTSN1 followed by LTN, small intensity peaks related to the epsilon phase $\left(\varepsilon-(\mathrm{Fe}, \mathrm{Cr})_{2} \mathrm{~N}_{1-z}\right)$ were observed.

GD-OES profiles (Fig. 10) confirm the presence of high amounts of nitrogen in the surface, cf. reflected-light microscopy results in Fig. 8.

\section{Discussion}

\subsection{Nitrogen solubility and effect of nitrogen on mechanical properties}

The high-temperature solution nitriding processes performed in the present study allowed the development of high nitrogen steels from conventional, commercial austenitic stainless steels. The nitrogen contents that can be dissolved in equilibrium with a $\mathrm{N}_{2}$ (partial) pressure depend on the initial chemical composition of the alloys and can be directly related to the presence of different contents of nitride forming and/or austenite stabilizing substitutional atoms in the selected stainless steel grades. The presence of manganese and chromium, both nitride-forming elements, increases the solubility of nitrogen [5], while an element like $\mathrm{Ni}$, not a nitride former, but an austenite stabilizer, will lower the solubility. Accordingly, the highest nitrogen content was found in the EN 1.4369, which has the highest Mn and Cr content and the lowest Ni content (cf. Fig. 1). A comparison of the predicted and experimental nitrogen solubilities in the three alloys for the applied conditions of high temperature solution nitriding (Fig.1d) shows an excellent agreement.

The addition of nitrogen has a dramatic (beneficial) impact on the mechanical properties of the selected stainless steels, in particular regarding the yield strength and hardness evolution upon straining.

The yield strength and hardness show a linear increase with the nitrogen content, irrespective of the initial chemical composition of the stainless steel grade. This shows that interstitial nitrogen is an effective solidsolution strengthener $[5,51]$. Solid solution strengthening often follows the square root of the solute concentration. This dependence was not confirmed for the present samples (cf. Fig. 2b). Rather, the approximate linear dependency in Fig. $2 \mathrm{~b}$ is in agreement with results in the literature for interstitial nitrogen in ferrite [52] and carbon in nickel [53]. 
The reduction in work hardening exponent, $n$, in the Voce equation with increasing nitrogen content, as clearly observed for AISI 304L and EN 1.4369 in Fig.2b, would be consistent with an increase of the stacking fault energy of austenite with nitrogen content. This would facilitate cross slip of dislocations and thereby reduction of the dislocation density by annihilation in stage III hardening. According to a recent review [54], nitrogen has been observed to either reduce or enhance the stacking fault energy in austenitic steels. For the present, relatively high nitrogen contents, reduction in the work hardening coefficient strongly suggests an increase in stacking fault energy. Importantly, the present experiments proved the effectiveness of HTSN treatments in obtaining high nitrogen steels from commercially available stainless steel grades, with nitrogen contents beyond those routinely attainable by adding nitrogen to the melt.

The high level of equivalent plastic strain reached for all the alloys confirms that, despite the strengthening effect of the interstitial atoms, the toughness of the stainless steel is not compromised in the investigated range of equivalent straining [5]. The occurrence of a yield drop at the transition from elastic to plastic straining (see inserts in Fig. 2a) is attributed to locking of dislocations by dissolution of interstitials in the dislocation core and/or the surrounding dislocation strain fields [55].

The yield strength is correlated to the hardness [56]. In Fig. 11 the experimentally determined yield stress is given as a function of the hardness for three equivalent strain levels $(0,0.15$ and 0.30$)$.

The dashed line in Fig. 11a represents the relation between yield stress and hardness for the case of plastic deformation. This suggests that plastic straining is more effective in enhancing the yield stress than nitrogen dissolution. On the other hand, interstitial alloying is effective in enhancing the hardness. This difference is attributed to the nitrogen-induced changes in the work-hardening (cf. Fig. $2 b$ and discussion above). As stated by Tabor [57], the representative strain involved in the determination of Vickers hardness by indentation is $8-10 \%$. Accordingly, shifting the stress values in Fig. 11a to the values corresponding to strains of $0.09,0.24$ and 0.39 instead of $0,0.15$ and 0.30 yields a more or less linear relation as illustrated in Fig. $11 \mathrm{~b}$.

In addition nitrogen has a large impact on the Hall-Petch slope as determined for a Fe-18Cr-16Ni-10Mn austenitic steel in [58]. The EN 1.4369 alloy is the only one containing significant amounts of nitrogen in the as-received condition where the grain size is smallest. Using Hall-Petch slopes from [58] determined for nitrogen concentrations of $0.17 \mathrm{wt} \%$ and $0.54 \mathrm{wt} \%$, which are the ones closest to the 0.23 and $0.45 \mathrm{wt} \%$ of 
the EN 1.4369 in the as-received and HTSN1 conditions, and the corresponding grain sizes ( 30 and $75 \mu \mathrm{m})$

(see Tables 2 and 3) gives a yield stress contribution for the as-received condition that is only about $25 \mathrm{MPa}$ smaller than for the HTSN1 case, which explains the similar yield stress for these two samples. This interpretation is further supported by the hardness data in Fig. 3a, which shows a clear difference between the annealed and solution nitrided conditions. The hardness indents are small compared to the grain size and the hardness values are therefore not affected.

The nitrogen dissolved into the three stainless steels by the HTSN treatment contributes to an important stabilization of austenite (cf. Fig. 5), such that the development of strain-induced martensite is effectively hindered in the investigated range of equivalent strains. Also this observation would be consistent with an increase in stacking fault energy with nitrogen content, because strain-induced martensite formation according to the $\gamma \rightarrow \varepsilon \rightarrow \alpha^{\prime}$ mechanism [54] becomes less favourable. Indeed, application of the empirical relations for estimating the martensite start temperatures for $\varepsilon, M_{s}^{\varepsilon}$, and $\alpha^{\prime}, M_{s}^{\alpha \prime}$, [59] to the present alloy compositions before and after solution nitriding shows a strong decrease of both $M_{S}^{\varepsilon}$ and $M_{s}^{\alpha \prime}$ and a change from $M_{s}^{\varepsilon}>M_{s}^{\alpha \prime}$ for relativey low nitrogen content to $M_{s}^{\varepsilon}<M_{s}^{\alpha \prime}$ for the highest nitrogen contents. Even though the present work concerns solution nitriding over the entire sample thickness, such that a uniform nitrogen-concentration profile is obtained over the sample thickness, the results can be transferred to surface engineering of stainless steels where the outer 1-2 $\mathrm{mm}$ (or less) is enriched by nitrogen to achieve a stabilization of austenite (or a local conversion of ferrite to austenite), combined with substantial hardening. Such a treatment is industrially applied as a finishing treatment $[15,16]$, but could equally well be followed by additional surface engineering, as shot peening or low-temperature surface hardening by nitriding, carburizing or nitrocarburizing. For shot peening the enhanced austenite stability and higher saturation and yield stress (cf. Eq. 1 and Fig. 2b) can be exploited, while for low-temperature surface hardening the sensitivity of the process for strain-induced martensite is prevented $[60,61]$. The next section describes this aspect for HTSN followed by LTN.

\subsection{Low-temperature nitriding}

Low-temperature nitriding of the three austenitic stainless steels after HTSN and plastic deformation in partially dissociated ammonia gas atmosphere resulted in the formation of expanded austenite. 
In previous research activities, it was shown that the development of strain-induced martensite upon deformation has a detrimental effect on the nitriding behaviour of stainless steels, while the increase in dislocation density in a completely austenitic structure has a negligible influence on the low-temperature treatment [38].

In the present case, all the materials after high temperature solution nitriding and plastic deformation remain austenitic, due to the austenite-stabilizing effect of the dissolved nitrogen.

For the selected experimental conditions, prior plastic deformation has no observable effect on the LTN response, neither on the morphology of the case nor on the nitrogen distribution in the expanded austenite zone. Furthermore, and perhaps most importantly, no indications for the presence of $\mathrm{CrN}$ were observed with X-ray diffraction or reflected-light microscopy. Such CrN precipitation, which is generally observed during low temperature nitriding of deformed AISI 316 and AISI 304L, is detrimental for the corrosion resistance of the alloy, because it is associated with local $\mathrm{Cr}$ depletion. Absence of dark staining in the micrographs in Figs. 6 and 9 strongly suggests that such $\mathrm{Cr}$ depletion has not occurred and that the expanded austenite cases have superior electrochemical properties as compared to the substrate, which is confirmed in a separate study [62].

The present results confirm that nucleation of $\mathrm{CrN}$ and associated $\mathrm{Cr}$ depletion as observed in deformed stainless steels is not the immediate result of energetically favourable nucleation of $\mathrm{CrN}$ on dislocations in austenite, but necessitates the presence of strain-induced martensite (ferrite). An energetically favourable orientation relation between the crystal structures of ferrite and $\mathrm{CrN}$ [63-65] is held responsible for this. For all the studied materials, absence of strain-induced martensite effectively prevents the nucleation of $\mathrm{CrN}$ in expanded austenite for the investigated processing temperatures.

\section{Conclusions}

Three different commercially available stainless steels grades (AISI 316, AISI 304L and EN. 1.4369) were subjected to high temperature solution nitriding treatments. The resulting nitrogen contents depend on the composition of the alloys and the applied conditions used in the high temperature solution nitriding process and can be predicted by assuming thermodynamic equilibrium between the various steels and the applied nitrogen pressure. The dissolution of nitrogen in the stainless steel matrix resulted in a significant improvement of, in particular, the hardness, but also the yield stress of the steels, without impairing the 
toughness. Moreover, the dissolution of nitrogen effectively stabilized the austenitic phase and no straininduced martensite developed on subsequent deformation.

The homogenous nitrogen-enriched stainless steels obtained by solid solution nitriding, were subjected to plastic deformation and subsequent low-temperature nitriding. The low-temperature nitriding process led to the formation of an expanded austenite case.

The absence of strain-induced martensite has a beneficial influence on the nitriding behavior. The case depth is independent of the steel quality, the degree of deformation and nitrogen content after solid solution nitriding at high temperature. $\mathrm{CrN}$ precipitation was avoided, thereby maintaining the stainless properties of the steel.

The combination of the two treatments, solution nitriding and low-temperature nitriding enables to improve the mechanical properties of bulk and surface for the selected commercially available alloys.

\section{Acknowledgement}

For the present research work, the authors gratefully acknowledge the Research Fund for Coal and Steel for the financial support to the PressPerfect project. Furthermore the authors would like to thank Sandvik Materials Technology for providing part of the materials used during the investigation. High temperature solution nitriding of the stainless steels was performed by Expanite A/S.

\section{References}

[1] M.O. Speidel: HNS 88 Lille (France), The insitute of Metals, London, 1989, p. 92.

[2] K. Frisk M. Kikuchi, M. Kajihara: HNS 88 Lille (France), The insitute of Metals, London, 1989, p. 63.

[3] M.L.G. Byrnes, M. Grujicic, and W.S. Owen: Acta Metall., 1987, vol. 35, pp. 1853-62.

[4] E. Werner: Mater. Sci. Eng., 1988, vol. 101, pp. 93-98.

[5] J.W. Simmons: Mater. Sci. Eng. A, 1996, vol. 207, pp. 159-69. 
[6] L.A. Norström: Met. Sci., 1977, vol. 11, pp. 208-12.

[7] Y. Takahashi, K. Yoshida, M. Shimada, and E. Tada: Adv. Cryog. Eng. Mater., 1982, vol. 28, pp. 7381.

[8] R.P. Reed: JOM, 1989, vol. 41, pp. 16-21.

[9] J.R. Kearns and H.E. Deverell: Mater. Perform., 1987, vol. 26, pp. 18-28.

[10] M. Janik-Czachor: Corrosion, 1975, vol. 31, pp. 394-98.

[11] J. J. Eckenrod and C. W. Kovach: Properties of Austenitic Stainless Steels Their Weld Metals, American Society for Testing and Materials (ASTM), Philadelphia, 1979, pp. 17-41.

[12] M.O. Speidel: Materwiss. Werksttech., 2006, vol. 37, pp. 875-80.

[13] A.H. Satir-Kolorz and H.K. Feichtinger: Zeitschrift Fuer Met. Res. Adv. Tech., 1991, vol. 82, pp. 68997.

[14] G. Stein and I. Hucklenbroich: Mater. Manuf. Process., 2004, vol. 19, pp. 7-17.

[15] H. Berns: ISIJ Int., 1996, vol. 36, pp. 909-14.

[16] H. Berns and S. Siebert: ISIJ Int., 1996, vol. 36, pp. 927-31.

[17] Z.L. Zhang and T. Bell: Surf. Eng., 1985, vol. 1, pp. 131-136.

[18] K. Ichii, K. Fujimura and T. Takase: Technology Reports of Kansai University, 1986, vol. 27, pp. 135144.

[19] A. Leyland, D.B. Lewis, P.R. Stevenson and A. Matthews: Surf. Coat. Techn., 1993, vol. 62, pp. 608617.

[20] T.L. Christiansen and M.A.J Somers: Int. J. Mater. Res. Former. Zeitschrift Fuer Met., 2009, vol. 100, pp. 1361-77.

[21] T. Bell: Key Eng. Mater., 2008, vol. 373-374, pp. 289-95.

[22] H. Dong: Int. Mater. Rev., 2010, vol. 55, pp. 65-98.

[23] M.A.J. Somers and T.L. Christiansen: in Thermochemical Surface Engineering of Steel, eds. E.J Mittemeijer and M.A.J. Somers, WoodHead Publishing, pp. 557-579. 
[24] Z. Yu, X.I. Xu, L. Wang, J. Qiang, and Z. Hei: Surf. Coatings Technol., 2002, vol. 153, pp. 125-30.

[25] M.K. Lei and X.M. Zhu: Surf. Coatings Technol., 2005, vol. 193, pp. 22-28.

[26] Y. Sun and T. Bell: Wear, 1998, vol. 218, pp. 34-42.

[27] C.X Li and T. Bell: Corros. Sci., 2004, vol. 46, pp. 1527-47.

[28] Committee of Stainless Steel Producers: Review of the Wear and Galling Characteristics of Stainless Steels, American Iron and Steel Institute, Washington, 1978.

[29] M. A.J Somers and T.L. Christiansen: J. Phase Equilibria Diffus., 2005, vol. 26, pp. 520-28.

[30] T. Bell: Surf. Eng., 2002, vol. 18, pp. 415-22.

[31] ASTM International: Standard Test Methods for Tension Testing of Metallic Materials [ Metric ], United States, 2004, p. E 8M - 04.

[32] T. L. Christiansen, T. S. Hummelshøj, and M.A.J. Somers: WO2012 146254-A1, 2012.

[33] T. L. Christiansen, T. S. Hummelshøj, and M.A.J. Somers: WO2013159781-A1, 2013.

[34] J.O. Andersson, T. Helander, L. Höglund, P. Shi, and B. Sundman: Calphad, 2002, vol. 26, pp. 273312.

[35] K. Frisk: Metall. Trans. A, 1990, vol. 21, pp. 2477-88.

[36] K. Frisk: Calphad, 1991, vol. 15, pp. 79-106.

[37] K. Frisk: Mater. Sci. Forum, 1999, vol. 318-320, pp. 95-102.

[38] F. Bottoli, G. Winther, T.L. Christiansen, and M.A.J. Somers: Metall. Mater. Trans. A, 2015, vol. 46, pp. 2579-90.

[39] F.A.P. Fernandes, T.L. Christiansen, and M.A.J. Somers: Proc. 28th Int. Conf. Surf. Modif. Technol., Valardocs, Tampere, Finland, 2014, pp. 223-33.

[40] C. Blawert, B.L. Mordike, G.A. Collins, K.T. Short, Y. Jiraskova, O. Schneeweiss, and V. Perina: Surf. Coatings Technol., 2000, vol. 128-129, pp. 219-25. 
[41] C. Blawert, H. Kalvelage, B.L. Mordike, G.A. Collins, K.T. Short, Y. Jirásková, and O. Schneeweiss: Surf. Coatings Technol., 2001, vol. 136, pp. 181-87.

[42] Z. Cheng, C.X. Li, H. Dong, and T. Bell: Surf. Coatings Technol., 2005, vol. 191, pp. 195-200.

[43] T.L. Christiansen and M.A.J. Somers: Surf. Interface Anal., 2005, vol. 21, pp. 445-55.

[44] J. Oddershede, T.L. Christiansen, K. Ståhl, and M.A J Somers: Scr. Mater., 2010, vol. 62, pp. 29093.

[45] J. Oddershede, T.L. Christiansen, K. Ståhl, and M.A.J. Somers: Steel Res. Int., 2011, vol. 82, pp. $1248-54$.

[46] D.H. Jack and K.H. Jack: Mater. Sci. Eng., 1973, vol. 11, pp. 1-27.

[47] K. H. Jack: Acta Crystallogr., 1952, vol. 5, pp. 404-11.

[48] K. H. Jack: R. Soc., 1948, vol. 195.

[49] K. H. Jack: Acta Crystallogr., 1950, vol. 3, pp. 392-94.

[50] H. Okamoto: J. Phase Equilibria, 1992, vol. 13, pp. 543-65.

[51] K.J. Irvine, R. J. Llewellyn, and F. B. Pickering: JISI, 1961, vol. 199, p. 153.

[52] Y. Nakada and A.S. Keh: Acta Metall., 1968, vol. 16, pp. 903-14.

[53] Y. Nakada and A.S. Keh: Metall. Trans., 1971, vol. 2, pp. 441-47.

[54] A. Das: Metall. Mater. Trans. A, 2016, vol. 47, pp. 748-768.

[55] A.H. Cottrell and B.H. Bilby: Proc. Phys. Soc. Sect. A, 1948, vol. 62, pp. 49-62.

[56] J.R. Cahoon, W.H. Broughton, and A.R. Kutzak: Metall. Trans., 1971.

[57] D. Tabor: Proc. R. Soc. A., 1948, vol. 192, p. 247.

[58] V.G. Gavriljuk, H. Berns, C. Escher, N.I. Glavatskaya, A. Sozinov, and Yu.N. Petrov: Mater. Sci. 
Forum, 1999, vol. 318-320, pp. 455-60.

[59] Q.X. Dai, X.N. Cheng, Y.T. Zhao, X.M. Luo, and Z.Z. Yuan: Mater. Char., 2004, vol.52, pp. 349-354.

[60] B.N. Mordyuk, G.I. Prokopenko, M.A. Vasylyev, and M.O. Lefimov: Mater. Sci. Eng. A, 2007, vol. 458, pp. 253-61.

[61] T.S. Wang, B. Lu, M. Zhang, R.J. Hou, and F.C. Zhang: Mater. Sci. Eng. A, 2007, vol. 458, pp. 24952.

[62] F. Bottoli, M. S. Jellesen, T.L. Christiansen, G. Winther, and M.A.J. Somers: Electrochemical characterization and crevice corrosion performance of high temperature solid-solution nitrided and low-temperature nitrided austenitic stainless steel., submitted for publication

[63] M.A.J. Somers, R.M. Lankreijer, and E.J. Mittemeijer: Philos. Mag. A, 1989, vol. 59, pp. 353-78.

[64] P.M. Hekker, H.C.F. Rozendaal, and E. J. Mittemeijer: J. Mater. Sci., 1985, vol. 20, pp. 718-29.

[65] P.C. Van Wiggen, H.C.F. Rozendaal, and E.J. Mittemeijer: J. Mater. Sci., 1985, vol. 20, pp. 4561-82. 


\section{List of Tables}

Table 1: Chemical compositions of AISI 316, AISI 304L and EN 1.4369 in wt\% as determined by the suppliers, Lemvigh Muller and Sandvik Materials Technology

Table 2: Hardness and grain size distribution of the as-received stainless steels.

Table 3: Nitrogen content in wt \% determined with inert gas fusion thermal conductivity detection (LECO TN 500 analyser) and grain grain-size after solid solution treatment.

Table 1: Chemical compositions of AISI 316, AISI 304L and EN 1.4369 in wt\% as determined by the suppliers, Lemvigh Muller and Sandvik Materials Technology.

\begin{tabular}{cccccccc}
\hline & $\boldsymbol{C}$ & $\mathrm{Si}$ & $\mathbf{M n}$ & $\mathbf{C r}$ & $\boldsymbol{N i}$ & $\mathbf{M o}$ & $\boldsymbol{N}$ \\
\hline AISI 316 & 0.07 & 0.4 & 1.6 & 17.0 & 10.55 & 2.0 & 0.05 \\
AISI 304L & 0.03 & 0.32 & 1.78 & 18.28 & 8.08 & - & - \\
EN 1.4369 & 0.09 & 0.74 & 5.92 & 18.58 & 7.11 & 0.18 & 0.23 \\
\hline
\end{tabular}

Table 2: Hardness and grain size distribution of the as-received stainless steels.

\begin{tabular}{ccc}
\hline & Hardness $\left(H V_{2 N}\right)$ & Grain Size $(\mu m)$ \\
\hline AISI 316 & 176 & $15(3)$ \\
AISI 304L & 186 & $15(1)$ \\
EN 1.4369 & 211 & $30(5)$ \\
\hline
\end{tabular}

Table 3: Nitrogen content in wt \% determined with inert gas fusion thermal conductivity detection (LECO TN 500 analyser) and grain grain-size after solid solution treatment.

\begin{tabular}{lcccc}
\cline { 2 - 5 } & \multicolumn{2}{c}{ Nitrogen Content (\%wt) } & \multicolumn{2}{c}{ Grain Size $(\boldsymbol{\mu m})$} \\
\cline { 2 - 5 } AISI 316 & HTSN1 & HTSN2 & HTSN1 & HTSN2 \\
\cline { 2 - 5 } AISI 304L & $0.306(1)$ & $0.448(2)$ & $50(8)$ & $51(7)$ \\
EN 1.4369 & $0.363(2)$ & $0.531(1)$ & $75(8)$ & $75(10)$ \\
& $0.450(1)$ & $0.646(3)$ & $75(15)$ & $75(10)$ \\
\hline
\end{tabular}




\section{Figure captions}

Figure 1: a-c Isopleths in the phase diagram showing the phase stability of austenite in the temperature range $1223-1623 \mathrm{~K}\left(950-1350{ }^{\circ} \mathrm{C}\right)$ vs. nitrogen content in the solid state. Superimposed on the isopleths, $\mathrm{N}_{2}$ isobars are given that would provide the equilibrium nitrogen contents. $d$ comparison of the predicted nitrogen content, as calculated with ThermoCalc, and the experimentally determined nitrogen content in the sample.

Figure 2a: True stress - true strain curve for AISI 316, AISI 304L and EN 1.4369 in as-received condition and after high-temperature solution nitriding treatment at 0.3 bar (HTSN1) and 0.9 bar (HTSN2) $\mathrm{N}_{2}$ pressure. Inserts show an enlargement of the transition from elastic to plastic region.

Figure 2b: Parameters obtained by fitting the Voce equation to the stress-strain curves in Fig. $2 \mathrm{a}$. The dashed lines give the upper yield limits as observed in Fig.2a.

Figure 3a: Hardness in the three selected alloys as a function of the equivalent strain......

Figure 3b: Hardness increase as a function of the interstitial nitrogen content in the three selected alloys in as-received and HTSN treated conditions, in unstrained and strained conditions to an equivalent strain of 0.15 and 0.30 . Note that for the unstrained condition also hardness values for HTSN treatment at 0.6 bar $\mathrm{N}_{2}$ gas pressure are included.......

Figure 4: X-ray diffractograms after plastic deformation of HTSN1 (a) and HTSN2 (b) treated steels for the highest tensile straining applied to the steels. i.e., $\varepsilon=0.42$ for AISI 316, $\varepsilon=0.45$ for AISI $304 \mathrm{~L}$ and $\varepsilon=0.50$ for EN 1.4369. No other phases than austenite were identified.

Figure 5: Cross-sectional micrographs of low-temperature nitrided steels: AISI 316 in HTNS (a) and deformed $\varepsilon=0.42$ (b) condition, AISI 304L in HTNS (c) and deformed $\varepsilon=0.45$ (d) condition, and EN 1.4369 in HTNS (e) and deformed $\varepsilon=0.50$ condition (f).

Figure 6: X-ray diffractograms of nitrided steels after HTSN1 and plastic deformation at the highest equivalent strain for the three alloys (Nitriding condition $\left.703 \mathrm{~K}\left(430^{\circ} \mathrm{C}\right), 20 \mathrm{~h}\right) .$.

Figure 7: GD-OES profiles of nitrogen and carbon for AISI 316 (a,d), AISI 304L (b,e) and EN 1.4369 (c,f) after HTSN1, deformation and low-temperature nitriding $\left(703 \mathrm{~K}\left(430^{\circ} \mathrm{C}\right), 20 \mathrm{~h}\right)$.

Figure 8: micrographs of low-temperature nitrided steels: AISI $316 \mathrm{HTSN}(\mathrm{a})$ and deformed $\varepsilon=0.42$ (b), AISI 304L HTSN (c) and deformed $\varepsilon=0.45$ (d), EN 1.4369 HTSN (e) and deformed $\varepsilon=0.50$ (f).

Figure 9: X-ray diffractograms of nitrided materials after HTSN2 and plastic deformation at the highest equivalent strain achieved for the three alloys (Nitriding condition $\left.703 \mathrm{~K}\left(430^{\circ} \mathrm{C}\right), 20 \mathrm{~h}\right) .$. 
Figure 10: GD-OES profiles of nitrogen and carbon for AISI $316(a, d)$, AISI 304L (b,e) and EN 1.4369 (c,f) after HTSN2, deformation and low-temperature nitriding $\left(703 \mathrm{~K}\left(430^{\circ} \mathrm{C}\right), 20 \mathrm{~h}\right)$

Figure 11: Yield stress for three levels of equivalent strain as a function of the hardness $\mathrm{HV}_{2.0 \mathrm{~N}}$. The dashed line indicates the straining/hardening that can be achieved by plastic deformation. a) experimental yield stress for each equivalent strain, b) stress corresponding to a strain $9 \%$ larger than the equivalent strain level. 


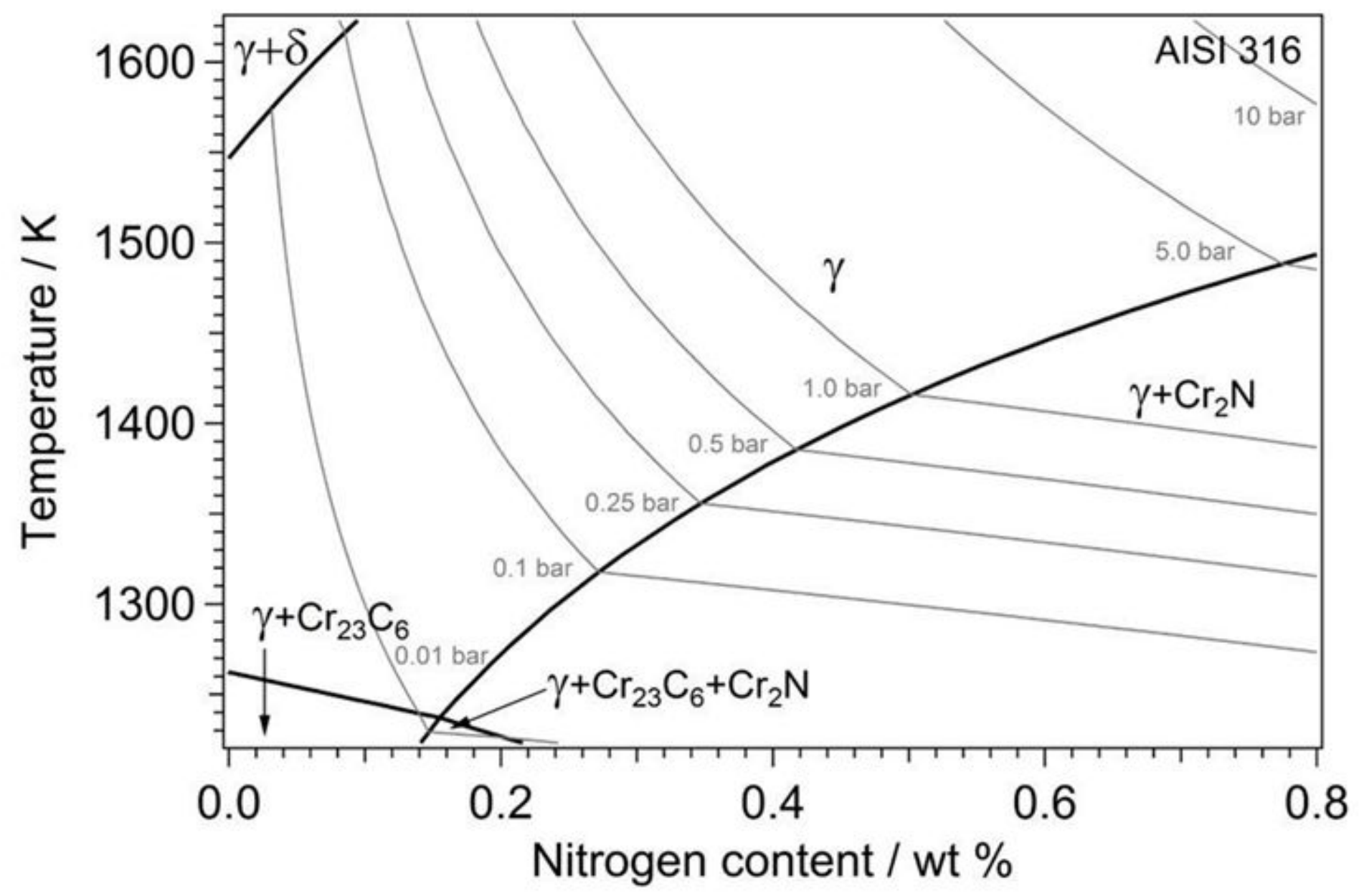

Figure 1: a-c Isopleths in the phase diagram showing the phase stability of austenite in the temperature range $1223-1623 \mathrm{~K}\left(950-1350^{\circ} \mathrm{C}\right)$ vs. nitrogen content in the solid state. Superimposed on the isopleths, $\mathrm{N}_{2}$ isobars are given that would provide the equilibrium nitrogen contents. d. comparison of the predicted nitrogen content, as calculated with ThermoCalc, and the experimentally determined nitrogen content in the sample. 


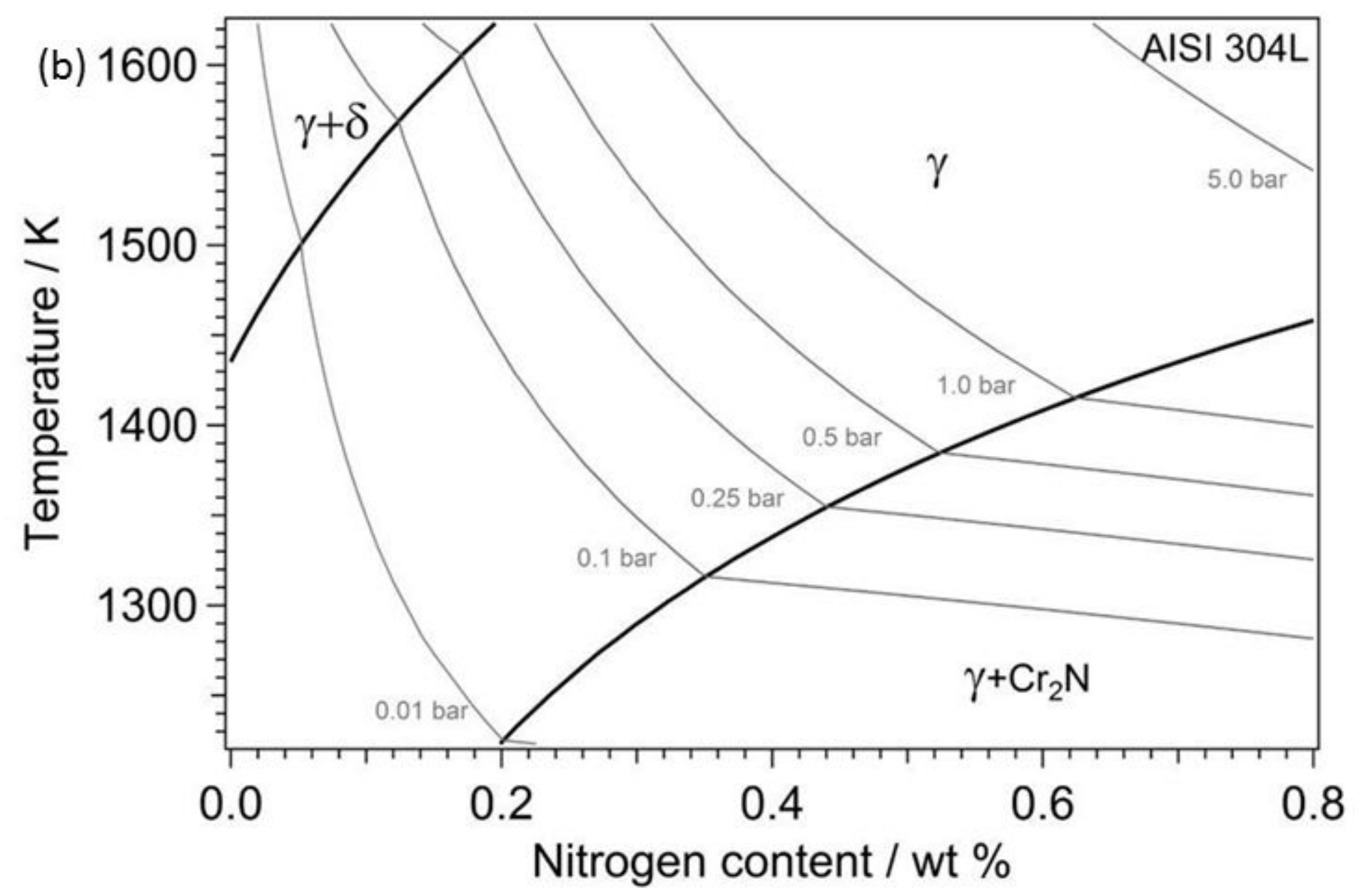

Figure 1: a-c Isopleths in the phase diagram showing the phase stability of austenite in the temperature range $1223-1623 \mathrm{~K}\left(950-1350^{\circ} \mathrm{C}\right)$ vs. nitrogen content in the solid state. Superimposed on the isopleths, $\mathrm{N}_{2}$ isobars are given that would provide the equilibrium nitrogen contents. d. comparison of the predicted nitrogen content, as calculated with ThermoCalc, and the experimentally determined nitrogen content in the sample. 


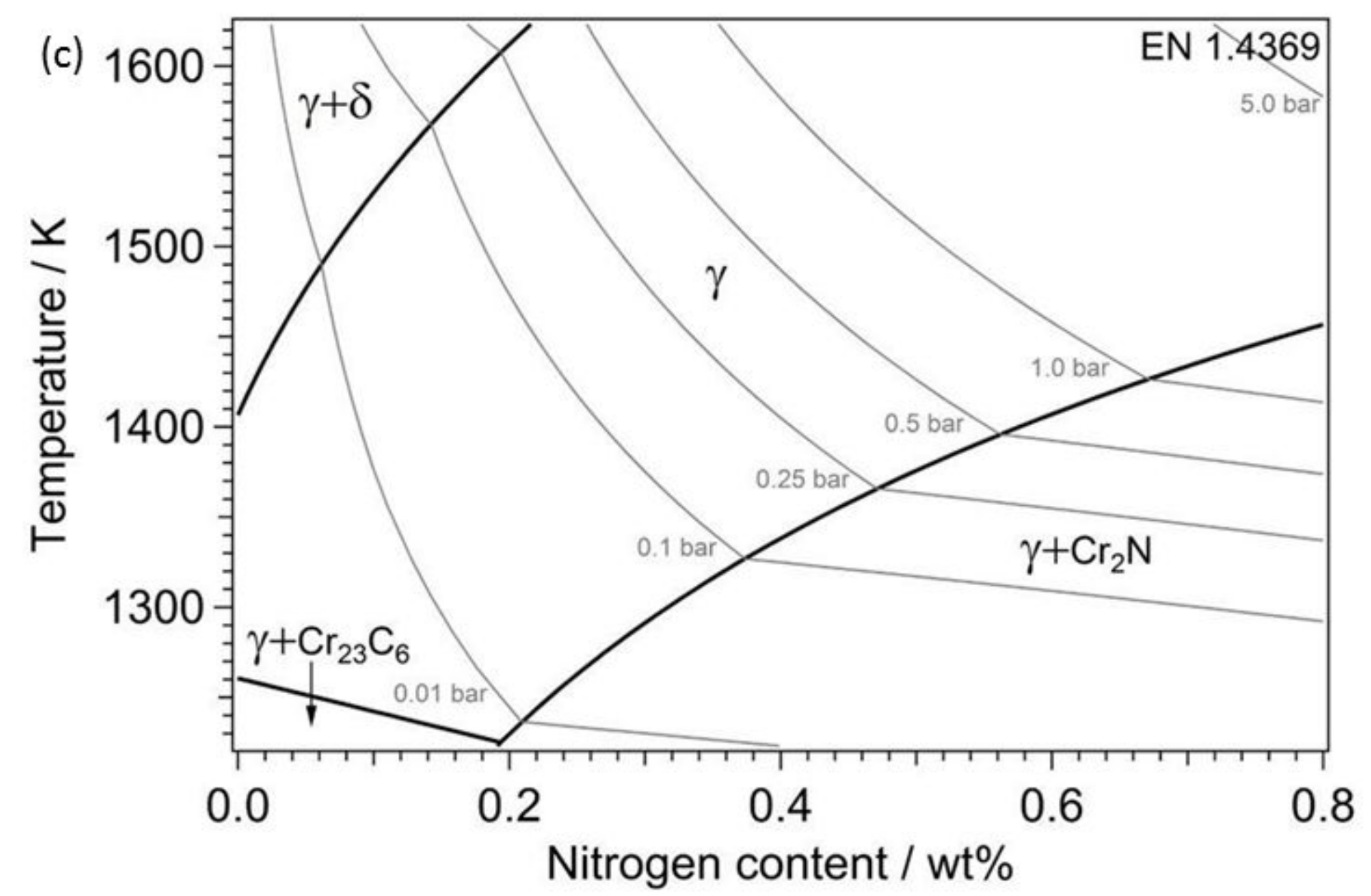

Figure 1: a-c Isopleths in the phase diagram showing the phase stability of austenite in the temperature range $1223-1623 \mathrm{~K}\left(950-1350^{\circ} \mathrm{C}\right)$ vs. nitrogen content in the solid state. Superimposed on the isopleths, $\mathrm{N}_{2}$ isobars are given that would provide the equilibrium nitrogen contents. $d$. comparison of the predicted nitrogen content, as calculated with ThermoCalc, and the experimentally determined nitrogen content in the sample. 
(d)

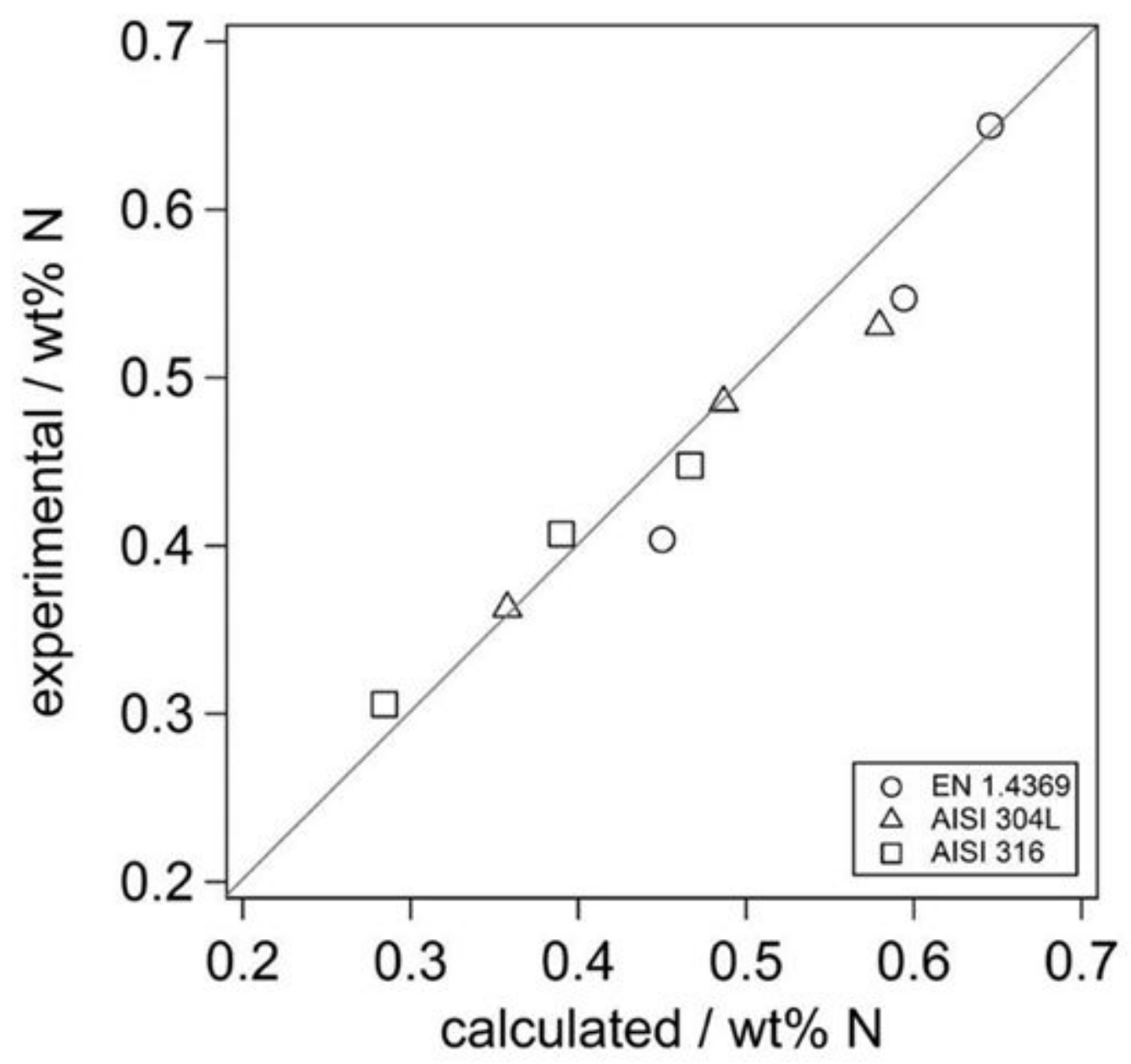

Figure 1: a-c Isopleths in the phase diagram showing the phase stability of austenite in the temperature range $1223-1623 \mathrm{~K}\left(950-1350^{\circ} \mathrm{C}\right)$ vs. nitrogen content in the solid state. Superimposed on the isopleths, $\mathrm{N}_{2}$ isobars are given that would provide the equilibrium nitrogen contents. d. comparison of the predicted nitrogen content, as calculated with ThermoCalc, and the experimentally determined nitrogen content in the sample. 


\section{Figure 2a}

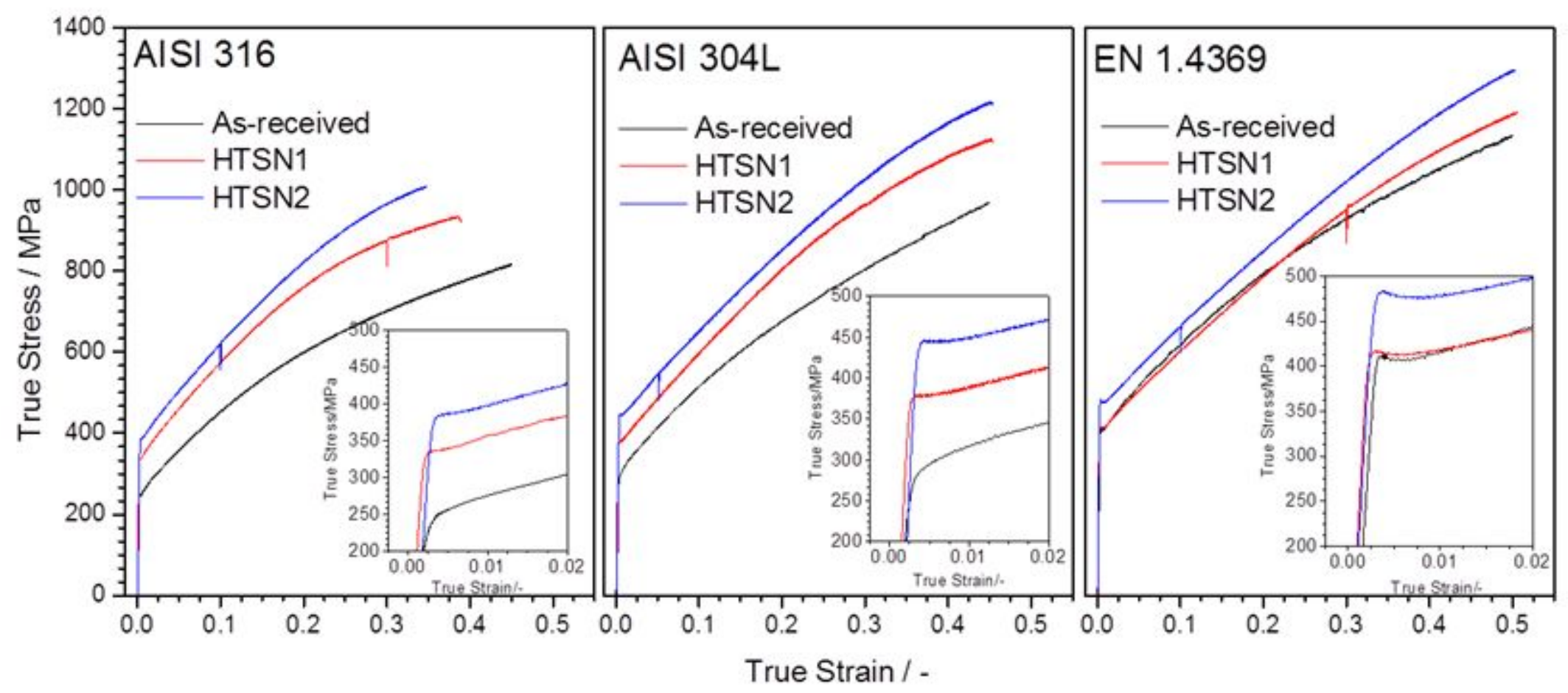

Figure 2a: True stress - true strain curve for AISI 316, AISI 304L and EN 1.4369 in asreceived condition and after high-temperature solution nitriding treatment at 0.3 bar (HTSN1) and 0.9 bar (HTSN2) $\mathrm{N}_{2}$ pressure. Insets show an enlargement of the transition from elastic to plastic region. 


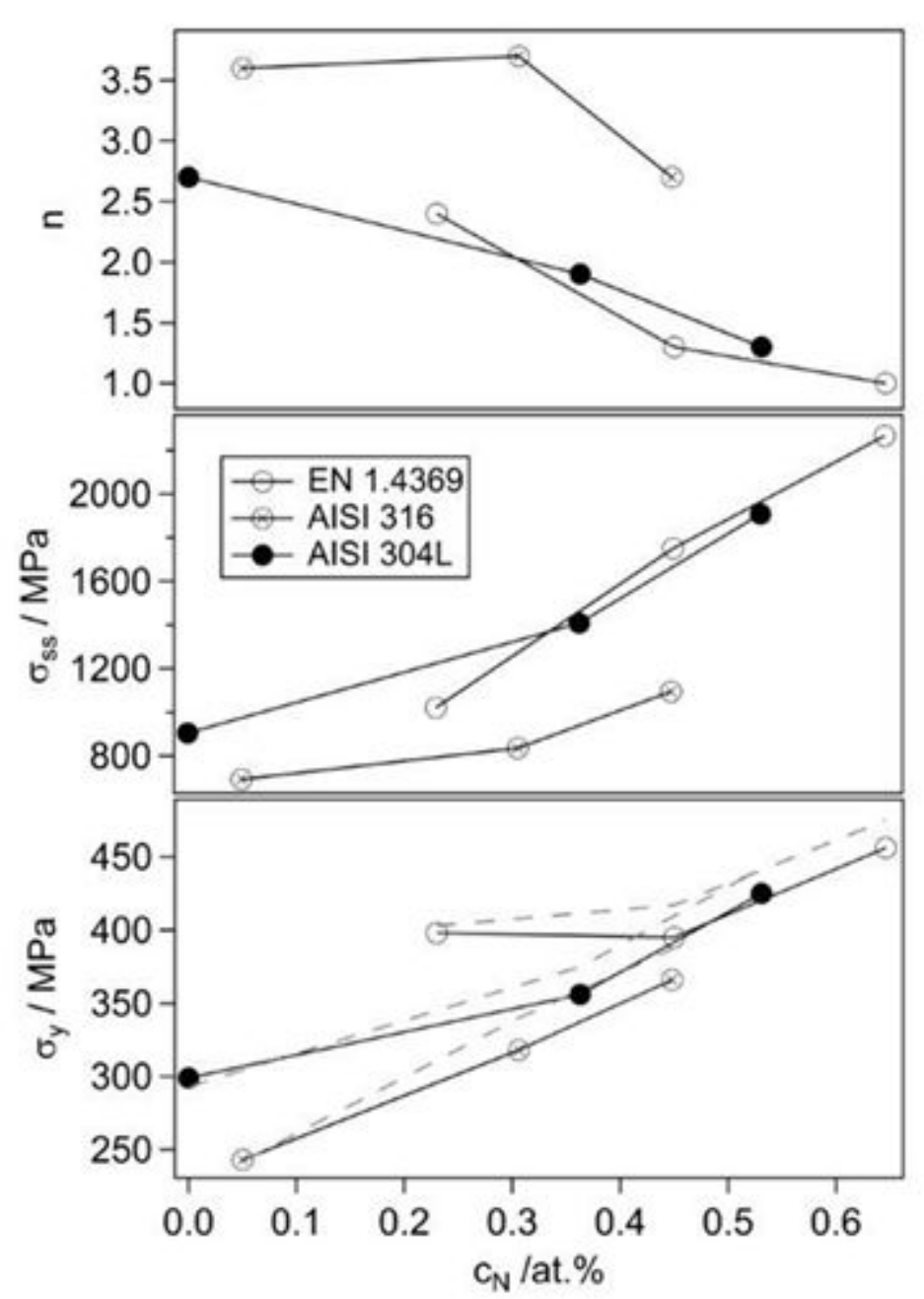

Figure $2 \mathrm{~b}$ : Parameters obtained by fitting the Voce equation to the stress-strain curves in Fig. $2 a$. The dashed lines give the upper yield limits as observed in Fig.3b. 
Figure 3a
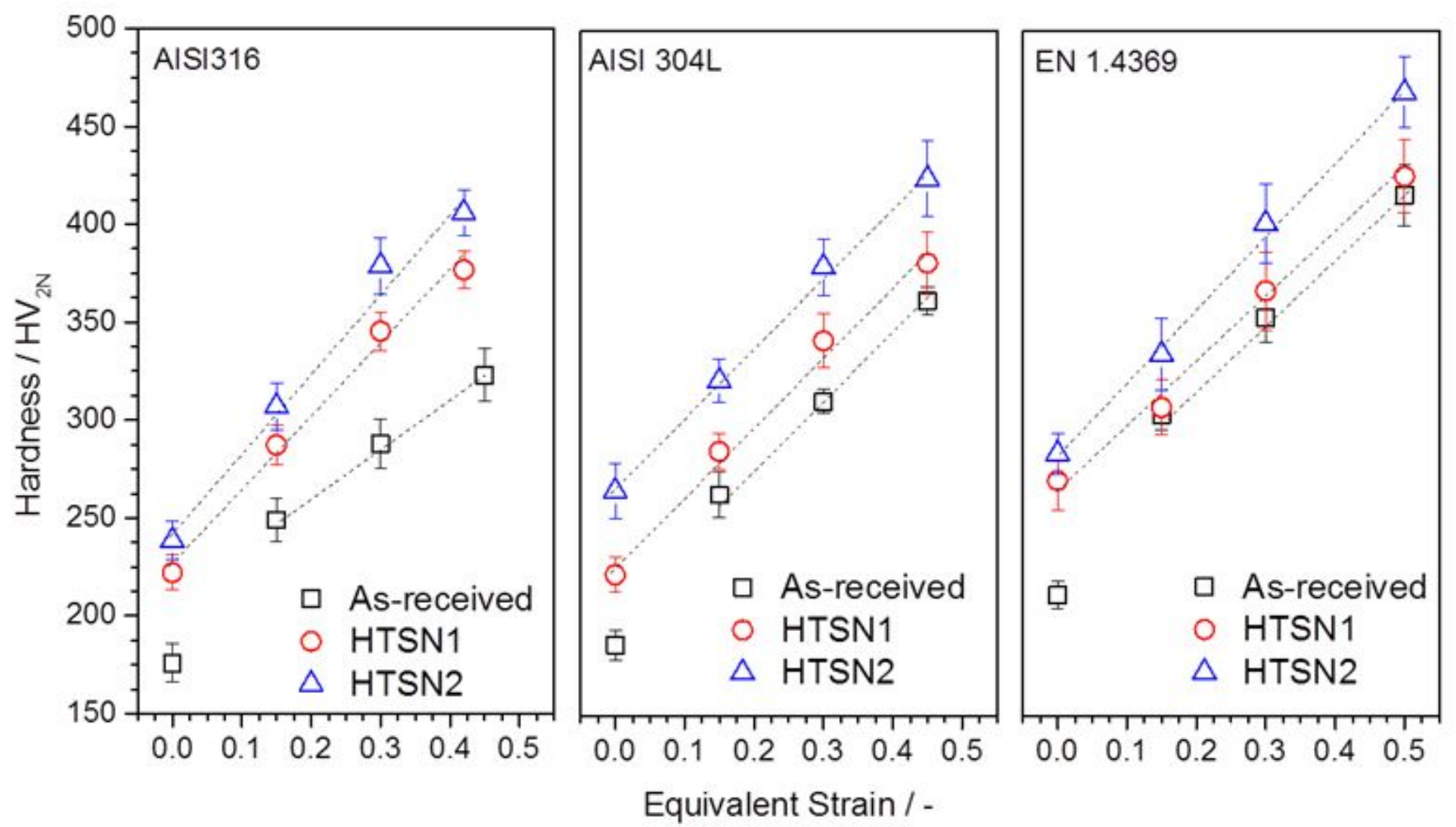

Figure 3a: Hardness in the three selected alloys as a function of the equivalent strain. 


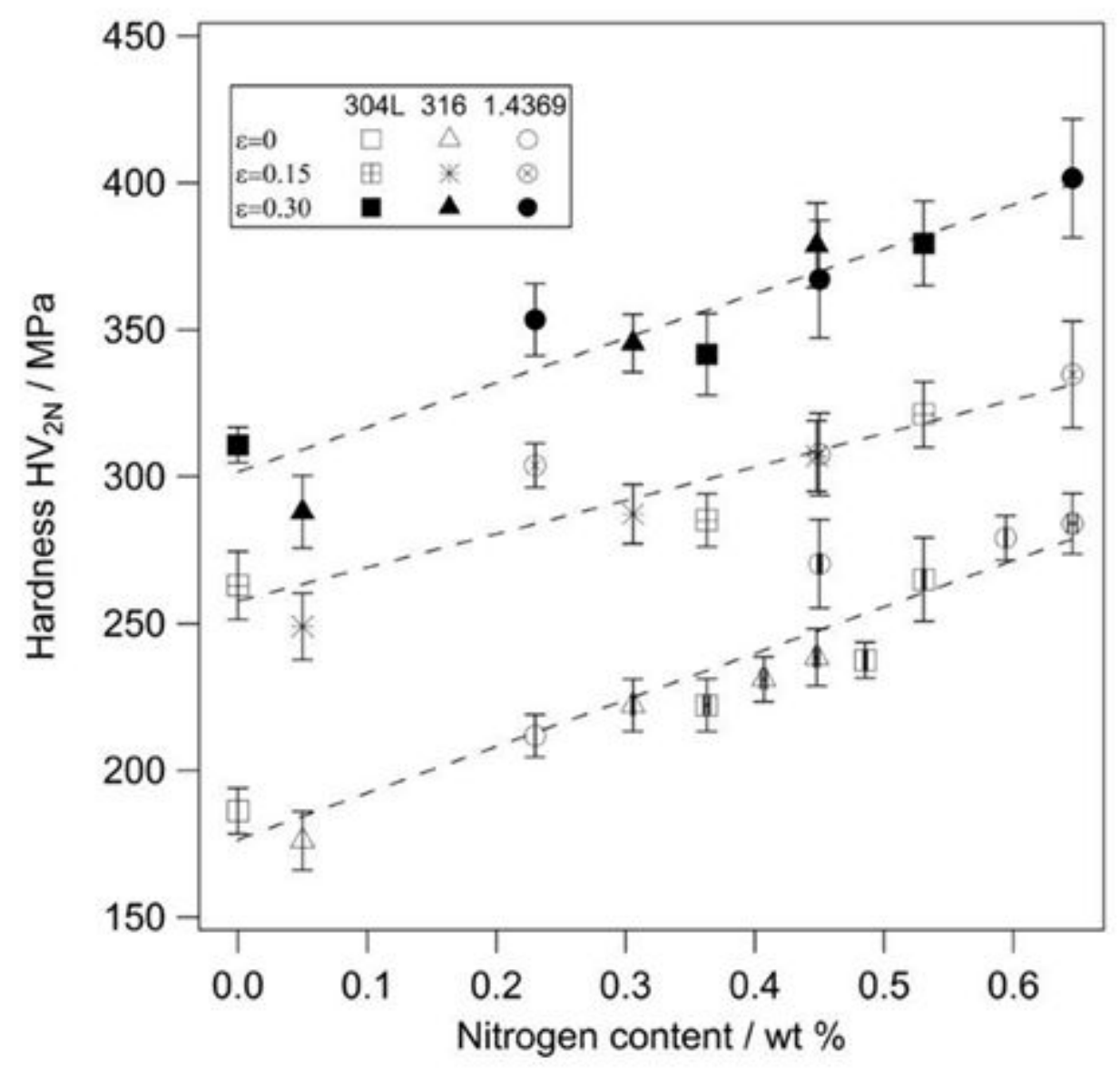

Figure 3b: Hardness increase as a function of the interstitial nitrogen content in the three selected alloys in as-received and HTSN treated conditions, in unstrained and strained conditions to an equivalent strain of 0.15 and 0.30 . Note that for the unstrained condition also hardness values for HTSN treatment at 0.6 bar $\mathrm{N}_{2}$ gas pressure are included. 


\section{Figure $4 a$}

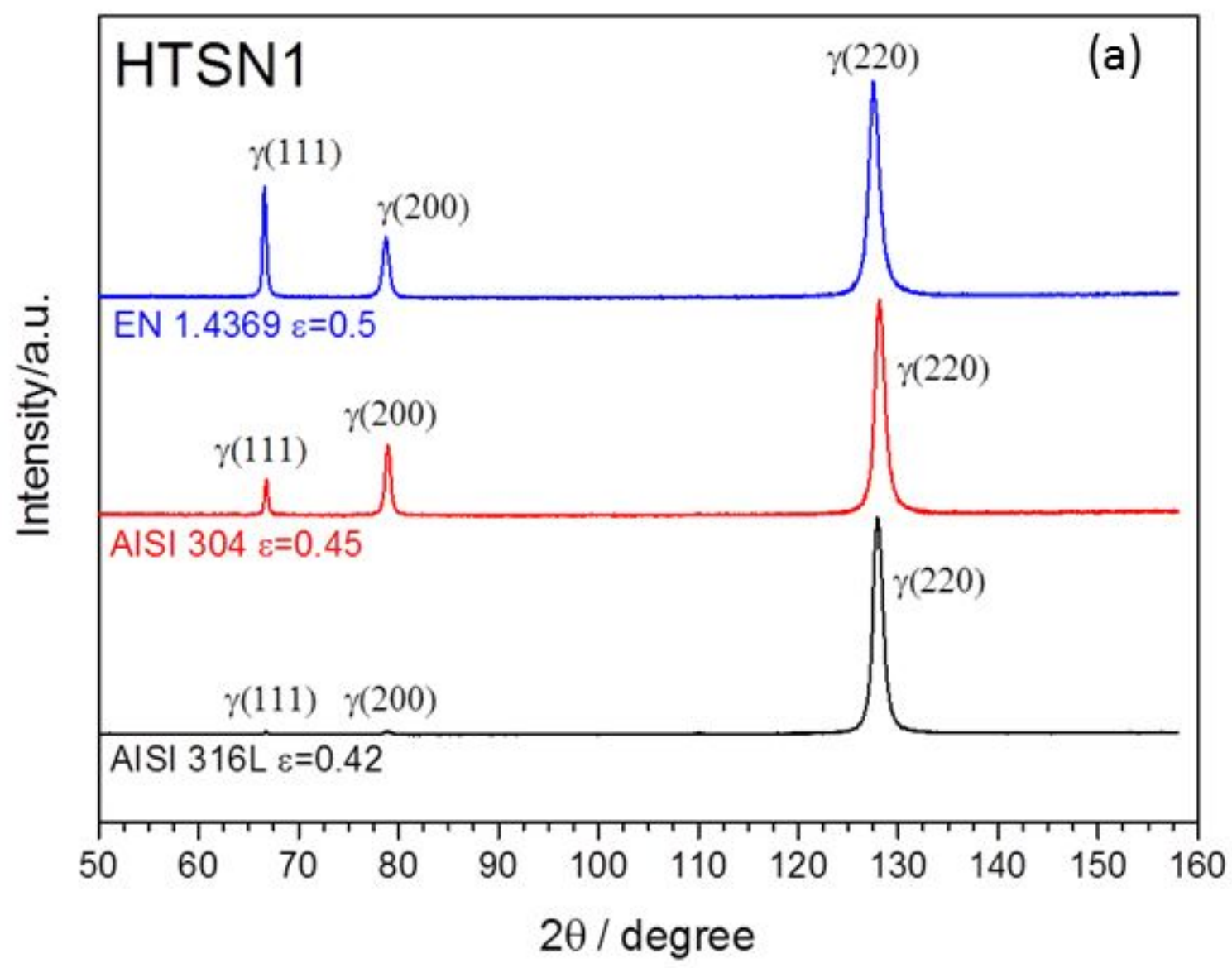

Figure 4: X-ray diffractograms after plastic deformation of HTSN1 (a) and HTSN2 (b) treated steels for the highest tensile straining applied to the steels. i.e., $\varepsilon=0.42$ for AISI $316, \varepsilon=0.45$ for AISI $304 \mathrm{~L}$ and $\varepsilon=0.50$ for EN 1.4369. No other phases than austenite were identified. 


\section{Figure $4 b$}

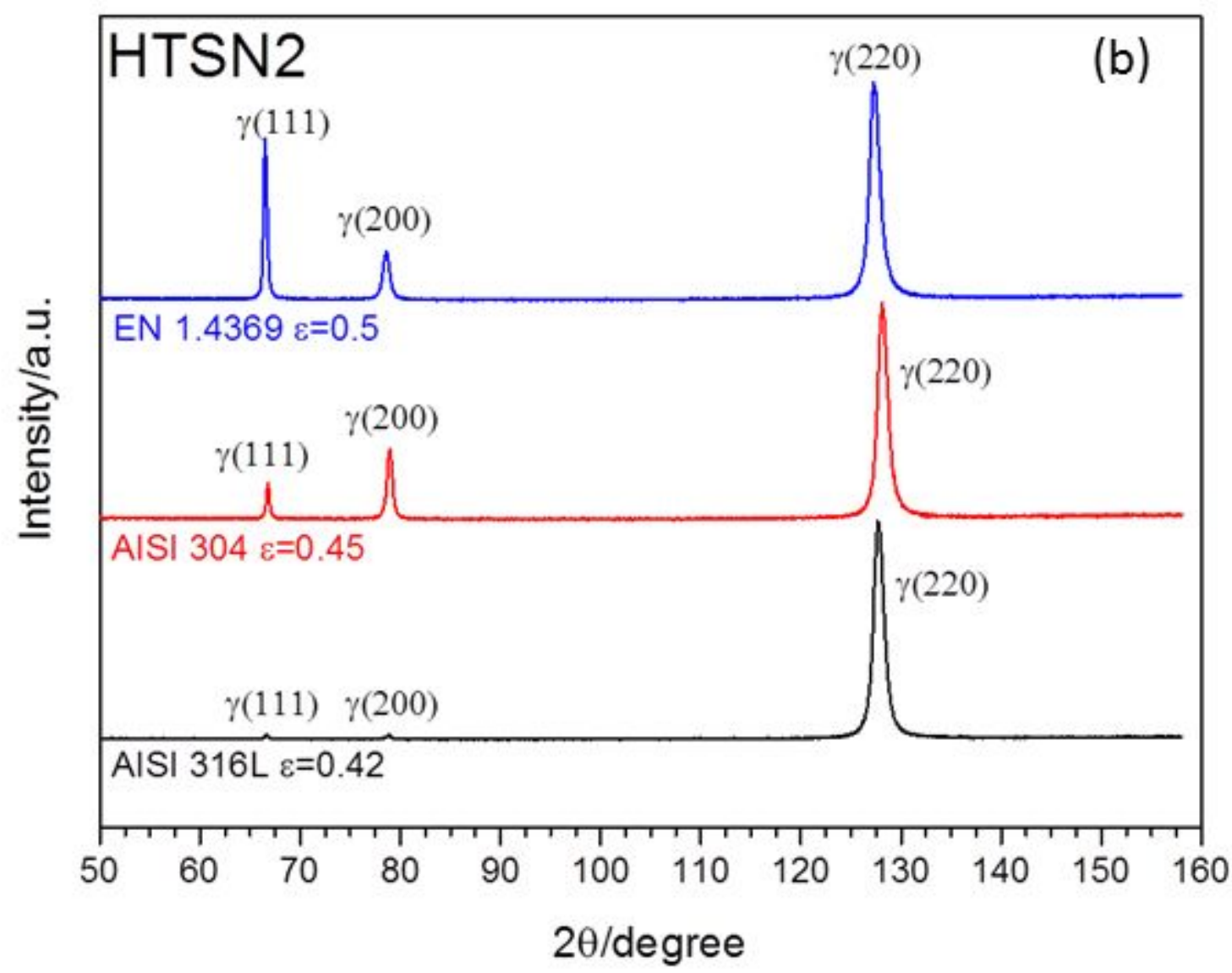

Figure 4: X-ray diffractograms after plastic deformation of HTSN1 (a) and HTSN2 (b) treated steels for the highest tensile straining applied to the steels. i.e., $\varepsilon=0.42$ for AISI $316, \varepsilon=0.45$ for AISI $304 \mathrm{~L}$ and $\varepsilon=0.50$ for EN 1.4369. No other phases than austenite were identified. 


\section{Figure 5a}

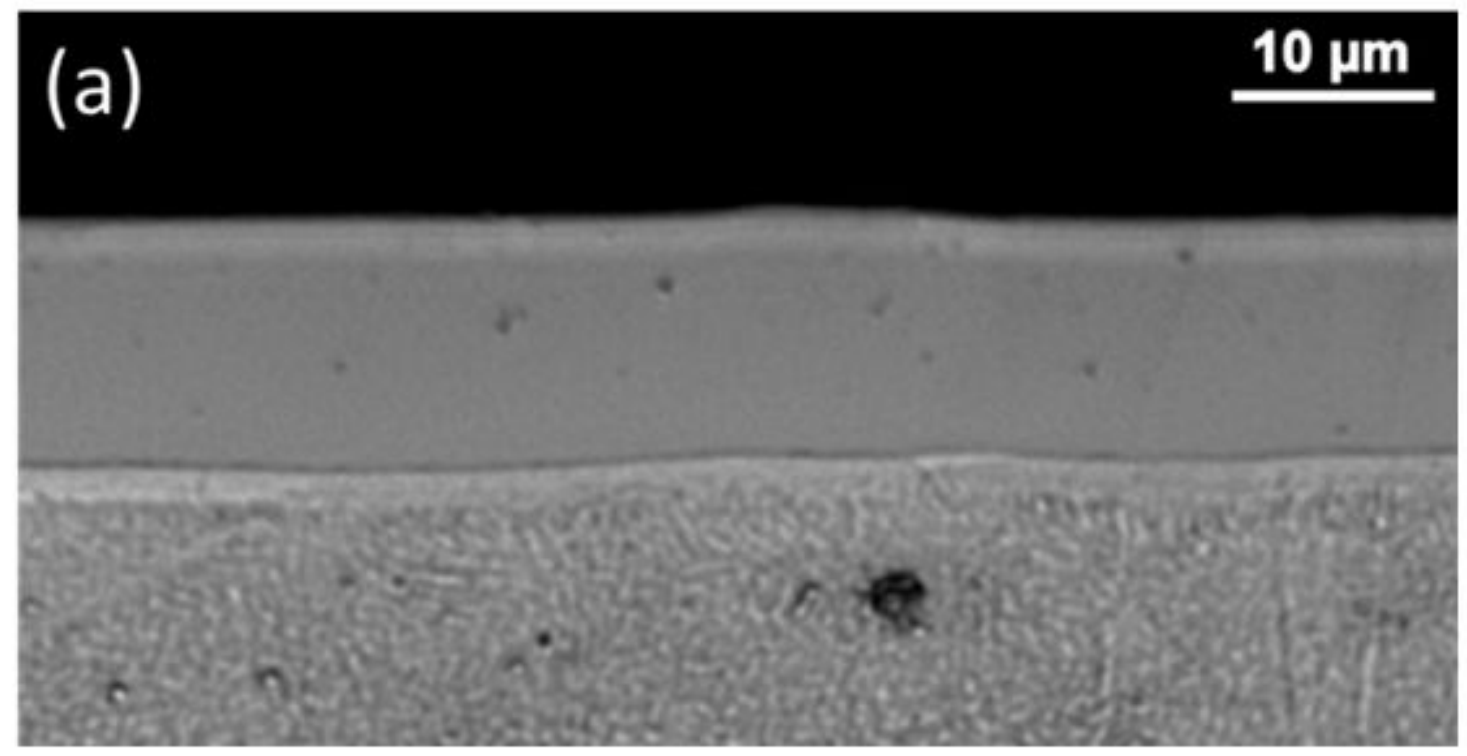

Figure 5: Cross-sectional micrographs of low-temperature nitrided steels: AISI 316 in HTNS (a) and deformed $\varepsilon=0.42$ (b) condition, AISI 304L in HTNS (c) and deformed $\varepsilon=0.45$ (d) condition, and EN 1.4369 in HTNS (e) and deformed $\varepsilon=0.50$ condition (f). 


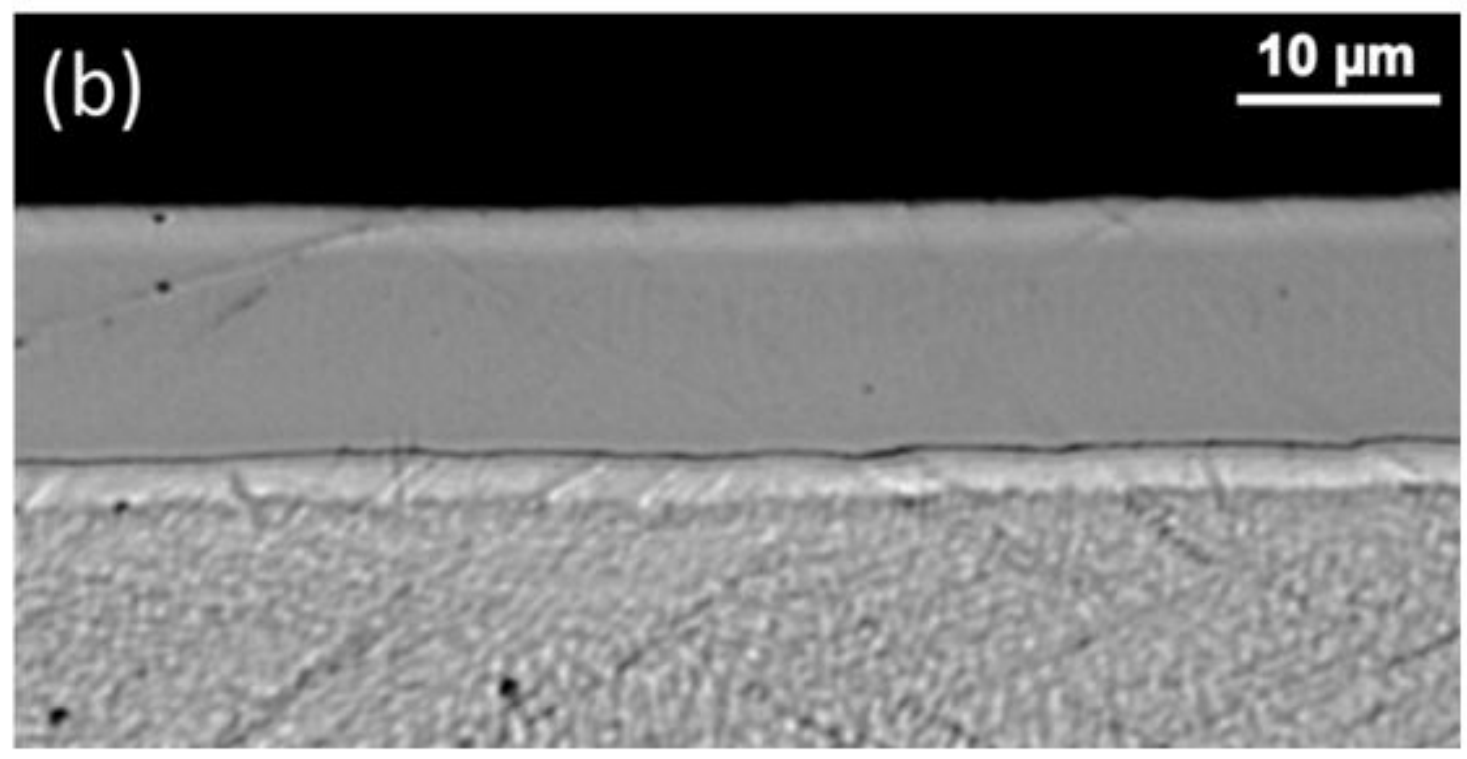

Figure 5: Cross-sectional micrographs of low-temperature nitrided steels: AISI 316 in HTNS (a) and deformed $\varepsilon=0.42$ (b) condition, AISI 304L in HTNS (c) and deformed $\varepsilon=0.45$ (d) condition, and EN 1.4369 in HTNS (e) and deformed $\varepsilon=0.50$ condition ( $f$ ). 


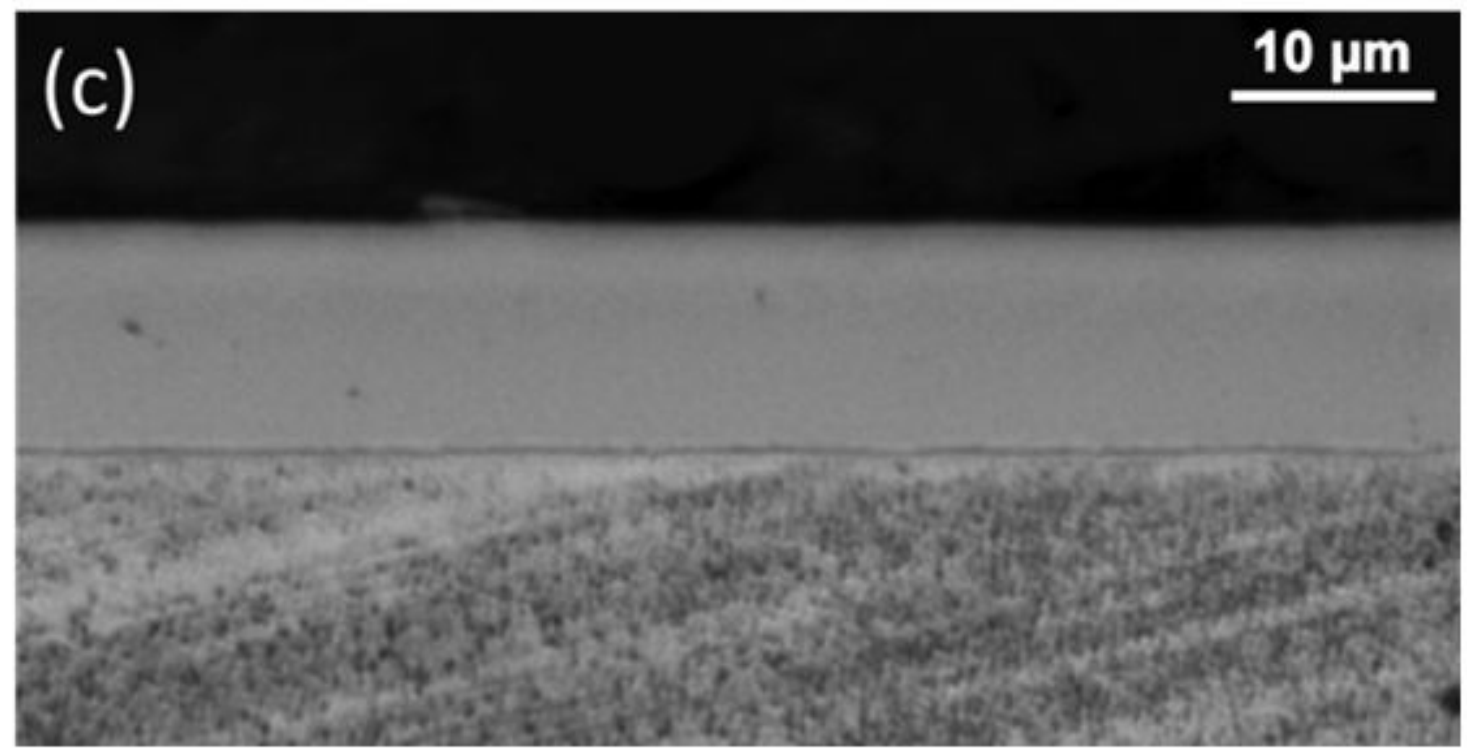

Figure 5: Cross-sectional micrographs of low-temperature nitrided steels: AISI 316 in HTNS (a) and deformed $\varepsilon=0.42$ (b) condition, AISI 304L in HTNS (c) and deformed $\varepsilon=0.45$ (d) condition, and EN 1.4369 in HTNS (e) and deformed $\varepsilon=0.50$ condition (f). 


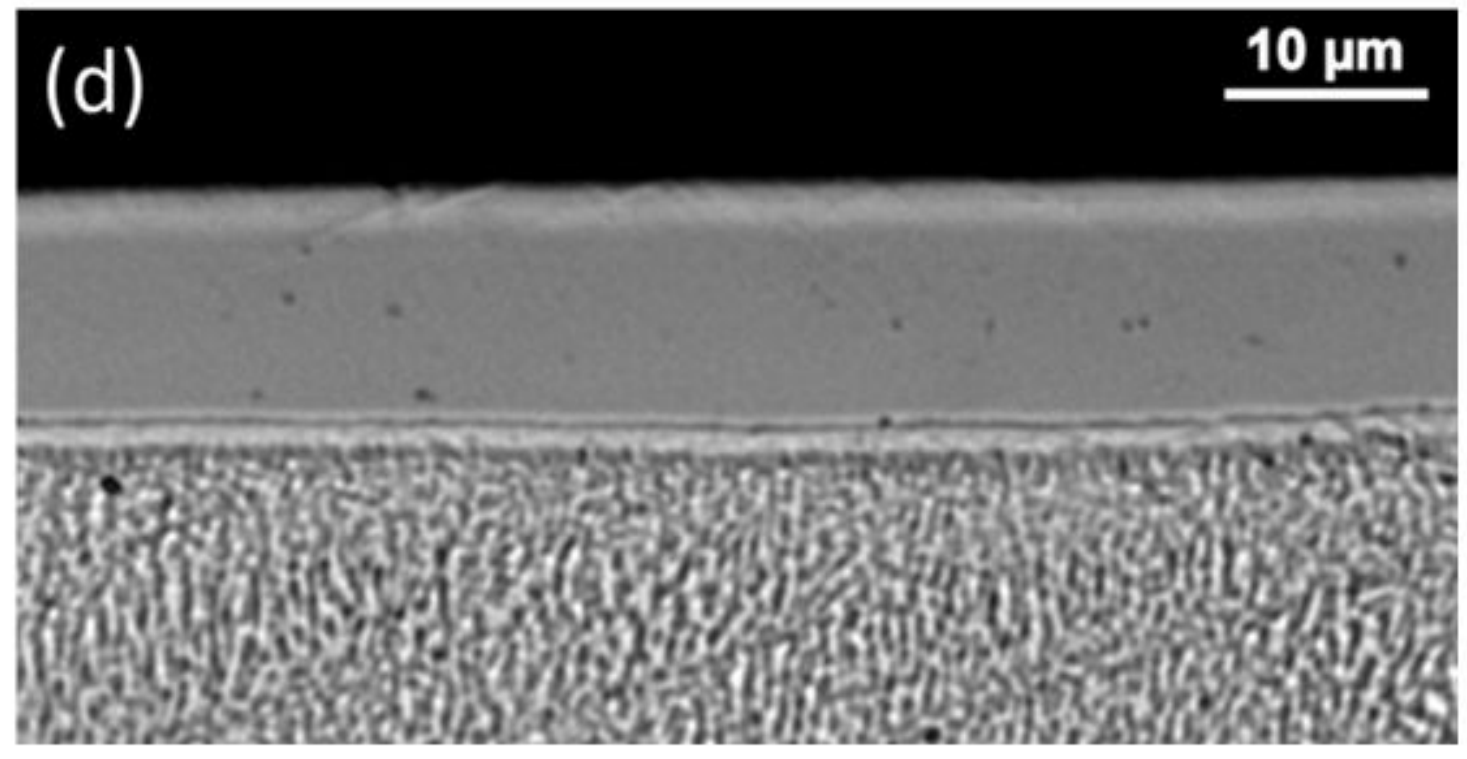

Figure 5: Cross-sectional micrographs of low-temperature nitrided steels: AISI 316 in HTNS (a) and deformed $\varepsilon=0.42$ (b) condition, AISI 304L in HTNS (c) and deformed $\varepsilon=0.45$ (d) condition, and EN 1.4369 in HTNS (e) and deformed $\varepsilon=0.50$ condition (f). 


\section{Figure $5 e$}

(e)

10 pm

Figure 5: Cross-sectional micrographs of low-temperature nitrided steels: AISI 316 in HTNS

(a) and deformed $\varepsilon=0.42$ (b) condition, AISI 304L in HTNS (c) and deformed $\varepsilon=0.45$ (d) condition, and EN 1.4369 in HTNS (e) and deformed $\varepsilon=0.50$ condition (f). 


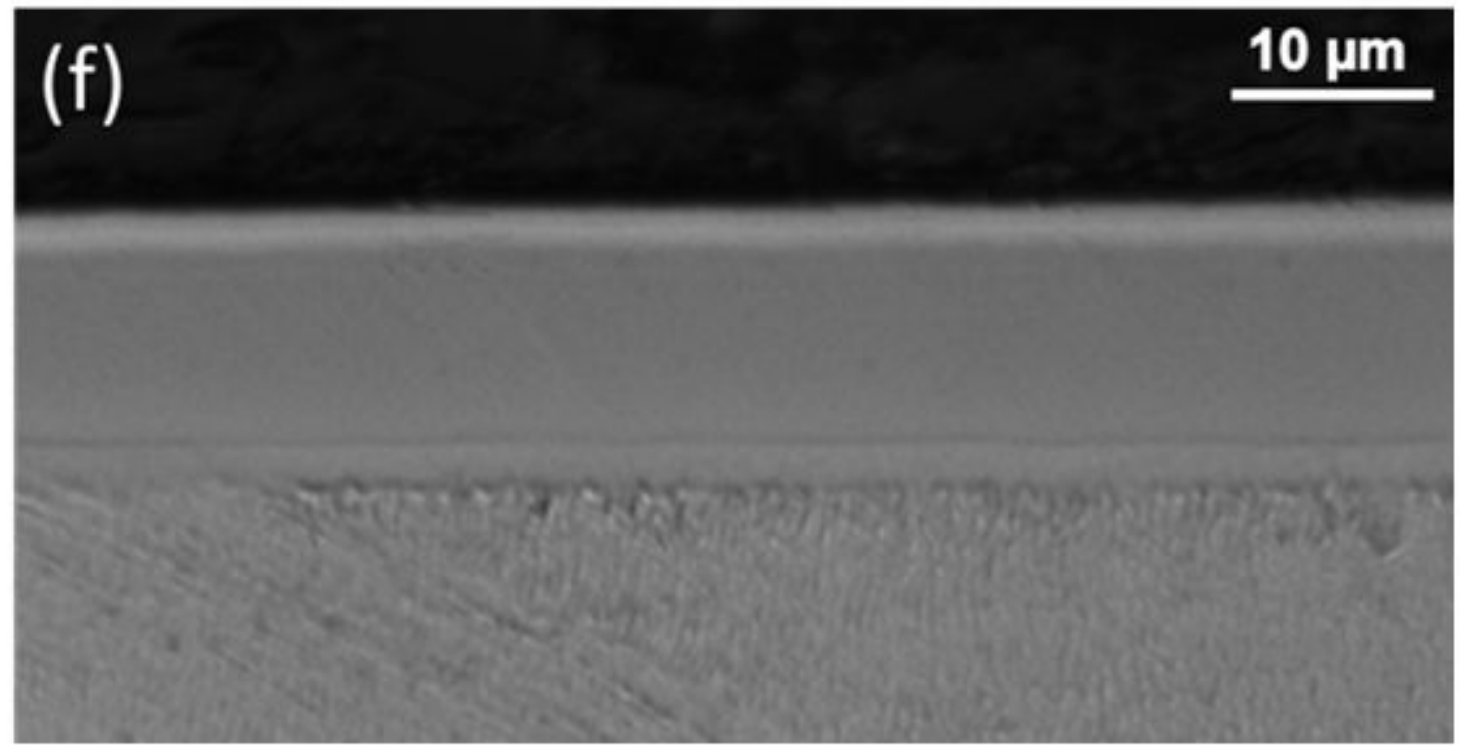

Figure 5: Cross-sectional micrographs of low-temperature nitrided steels: AISI 316 in HTNS (a) and deformed $\varepsilon=0.42$ (b) condition, AISI 304L in HTNS (c) and deformed $\varepsilon=0.45$ (d) condition, and EN 1.4369 in HTNS (e) and deformed $\varepsilon=0.50$ condition (f). 


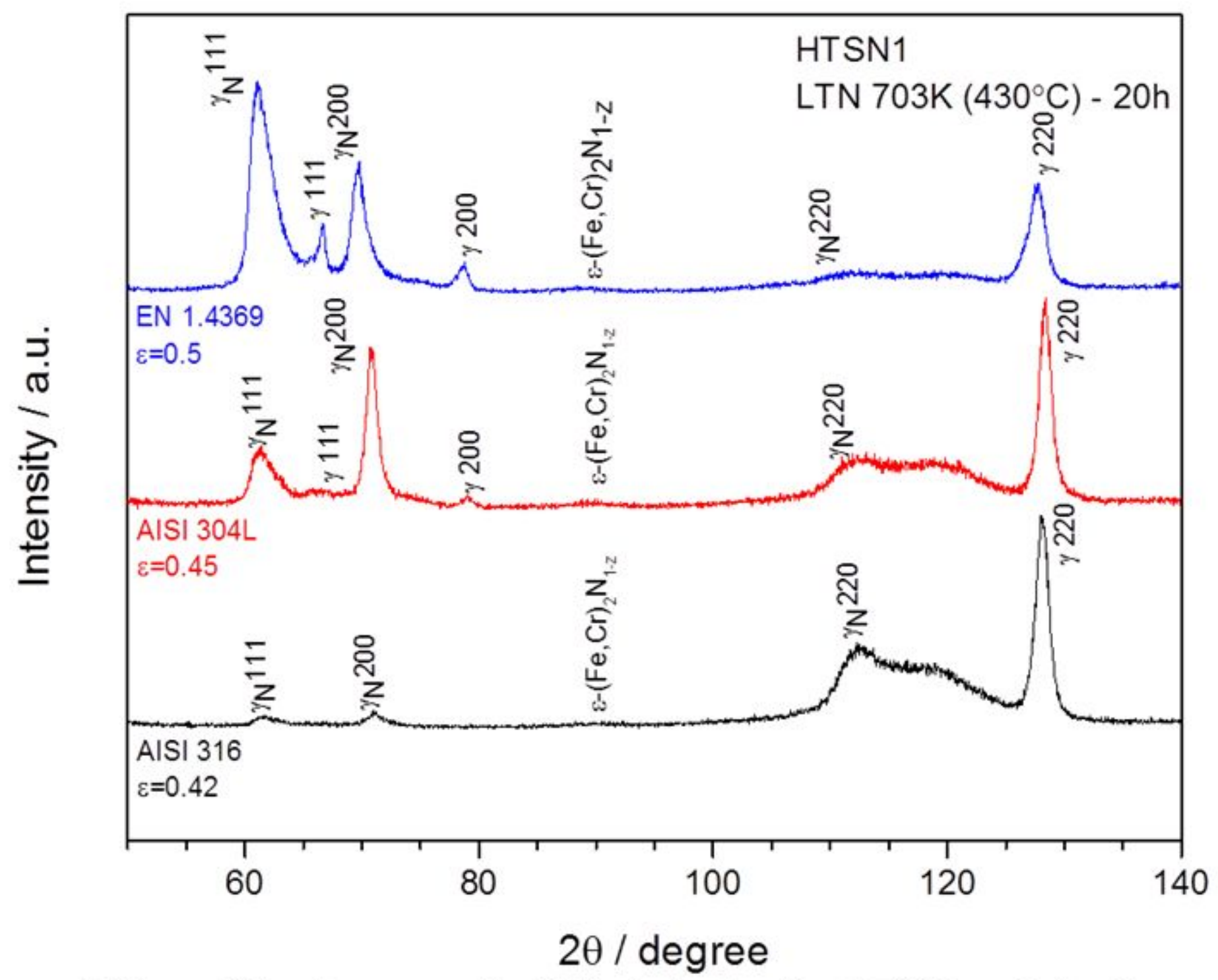

Figure 6: X-ray diffractograms of nitrided steels after HTSN1 and plastic deformation at the highest equivalent strain for the three alloys (Nitriding condition $\left.703 \mathrm{~K}\left(430^{\circ} \mathrm{C}\right), 20 \mathrm{~h}\right)$. 
(a)

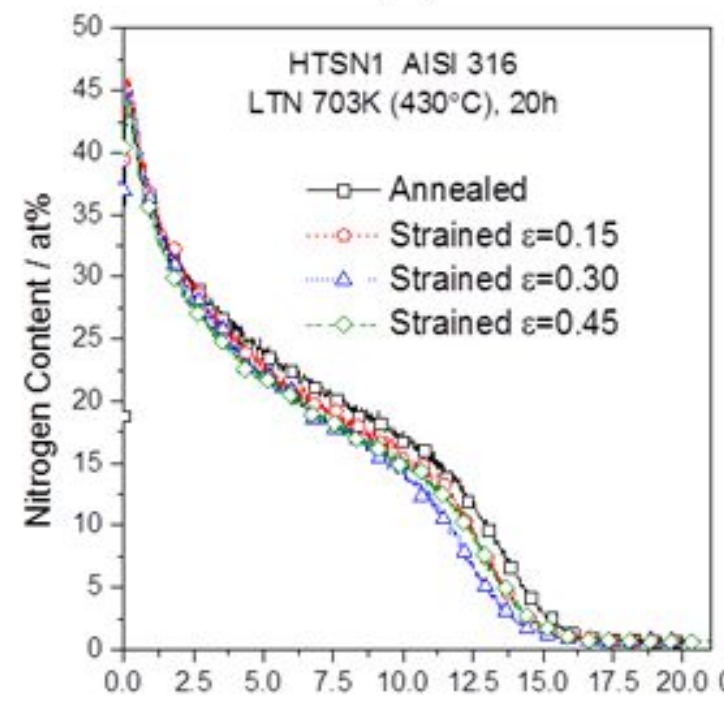

(d)

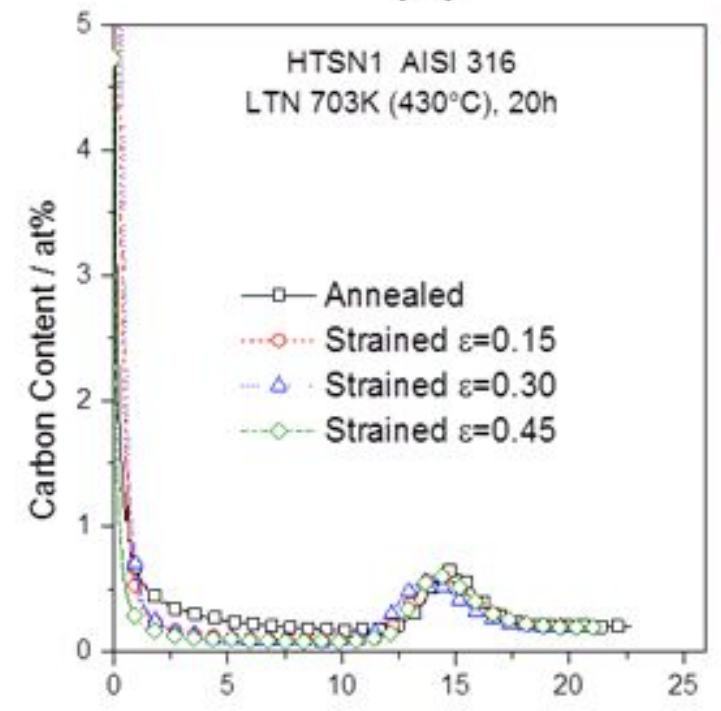

(b)

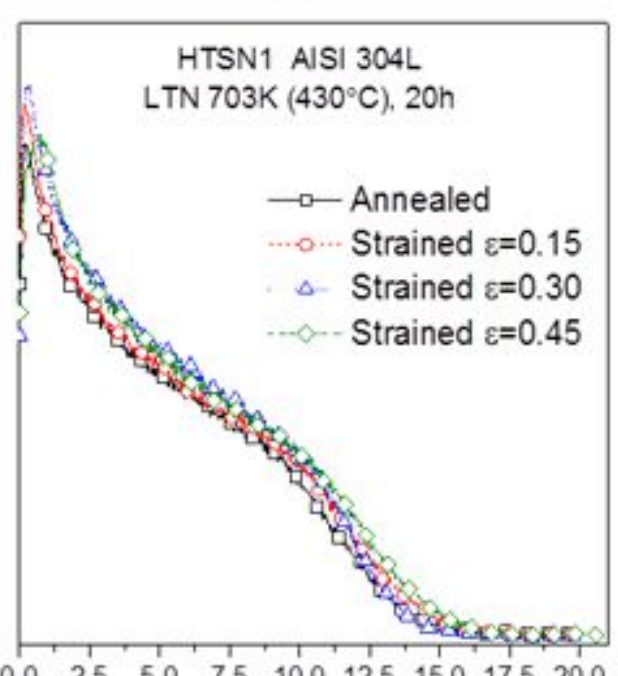

Depth / $\mu \mathrm{m}$

(e)

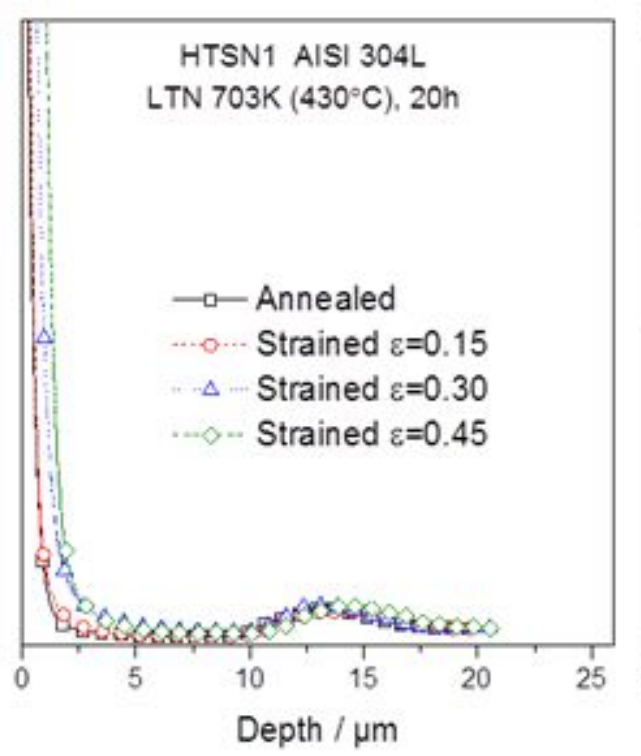

(c)

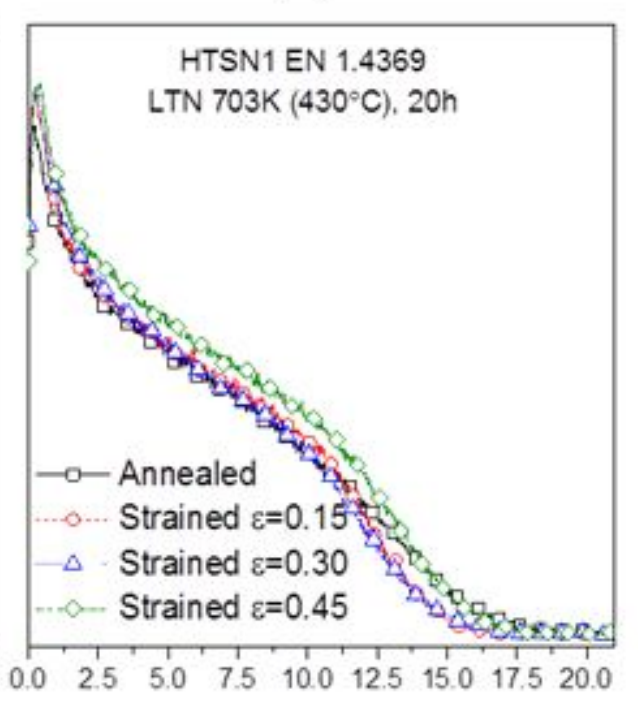

(f)

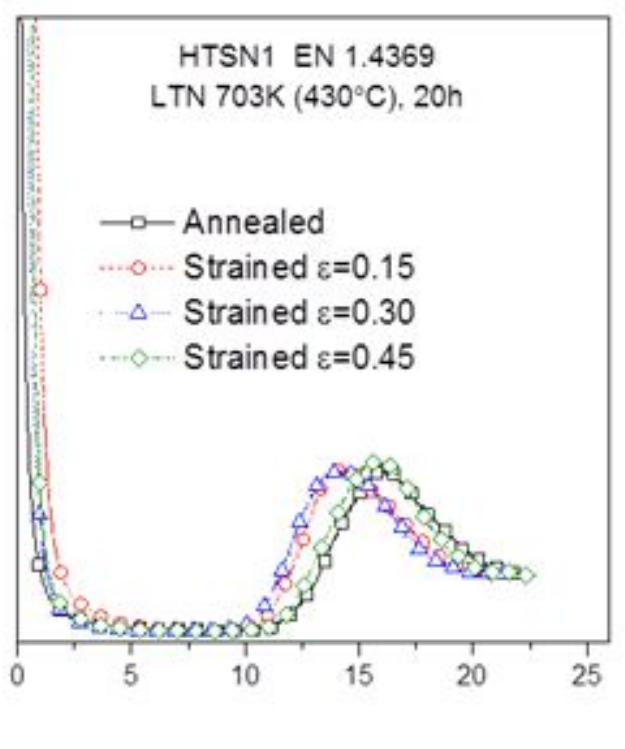

Figure 7: GD-OES profiles of nitrogen and carbon for AISI $316(a, d)$, AISI 304L (b,e) and EN 1.4369 (c,f) after HTSN1, deformation and low-temperature nitriding $\left(703 \mathrm{~K}\left(430^{\circ} \mathrm{C}\right), 20 \mathrm{~h}\right)$. 


\section{Figure $8 a$}

(a)

$10 \mathrm{pm}$

Figure 8: micrographs of low-temperature nitrided steels: AISI 316 HTSN (a) and deformed $\varepsilon=0.42$ (b), AISI 304L HTSN (c) and deformed $\varepsilon=0.45$ (d), EN $1.4369 \operatorname{HTSN}(e)$ and deformed $\varepsilon=0.50$ (f). 


\section{Figure $8 \mathrm{~b}$}

(b)

$10 \mu \mathrm{m}$

Figure 8: micrographs of low-temperature nitrided steels: AISI 316 HTSN (a) and deformed $\varepsilon=0.42$ (b), AISI 304L HTSN (c) and deformed $\varepsilon=0.45$ (d), EN $1.4369 \operatorname{HTSN}(e)$ and deformed $\varepsilon=0.50$ (f). 


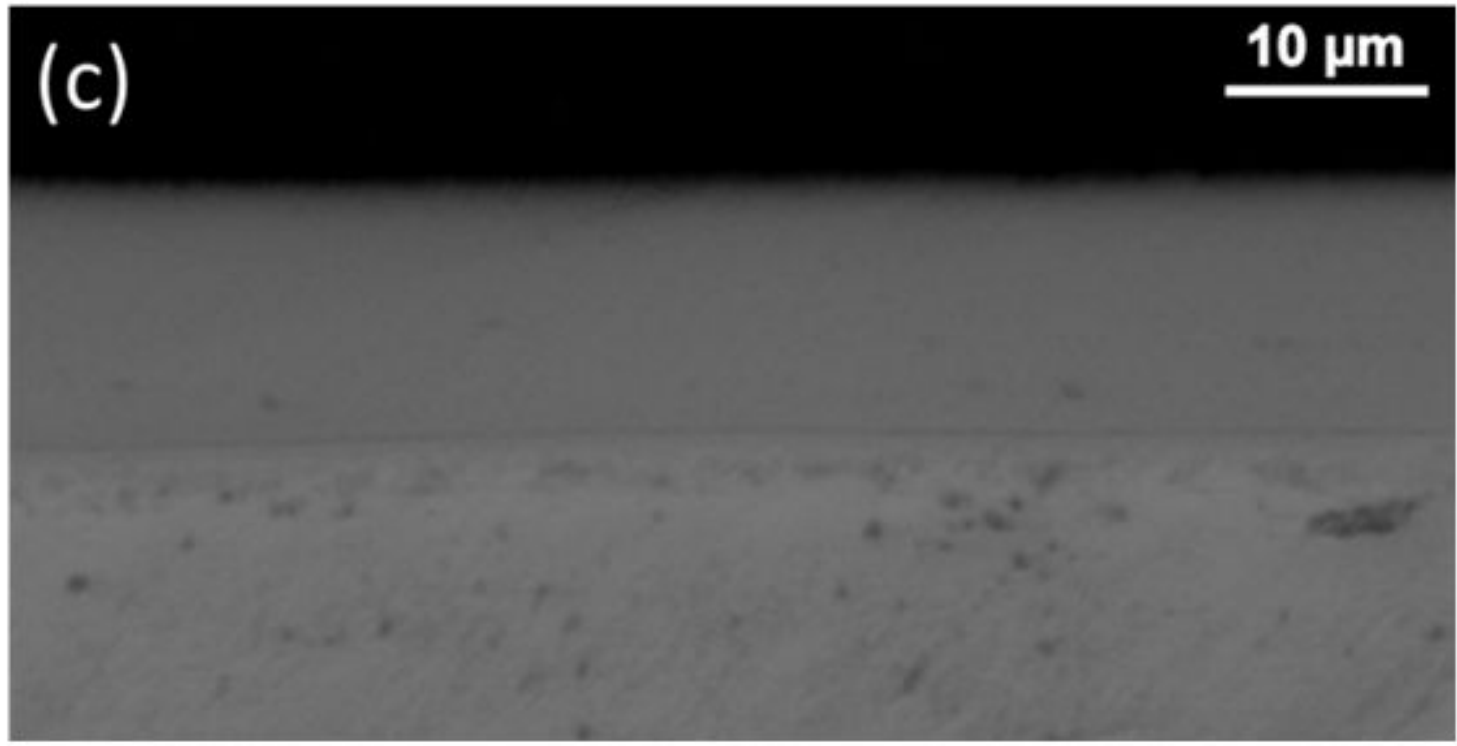

Figure 8: micrographs of low-temperature nitrided steels: AISI 316 HTSN (a) and deformed $\varepsilon=0.42$ (b), AISI 304L HTSN (c) and deformed $\varepsilon=0.45$ (d), EN $1.4369 \operatorname{HTSN}(e)$ and deformed $\varepsilon=0.50$ (f). 


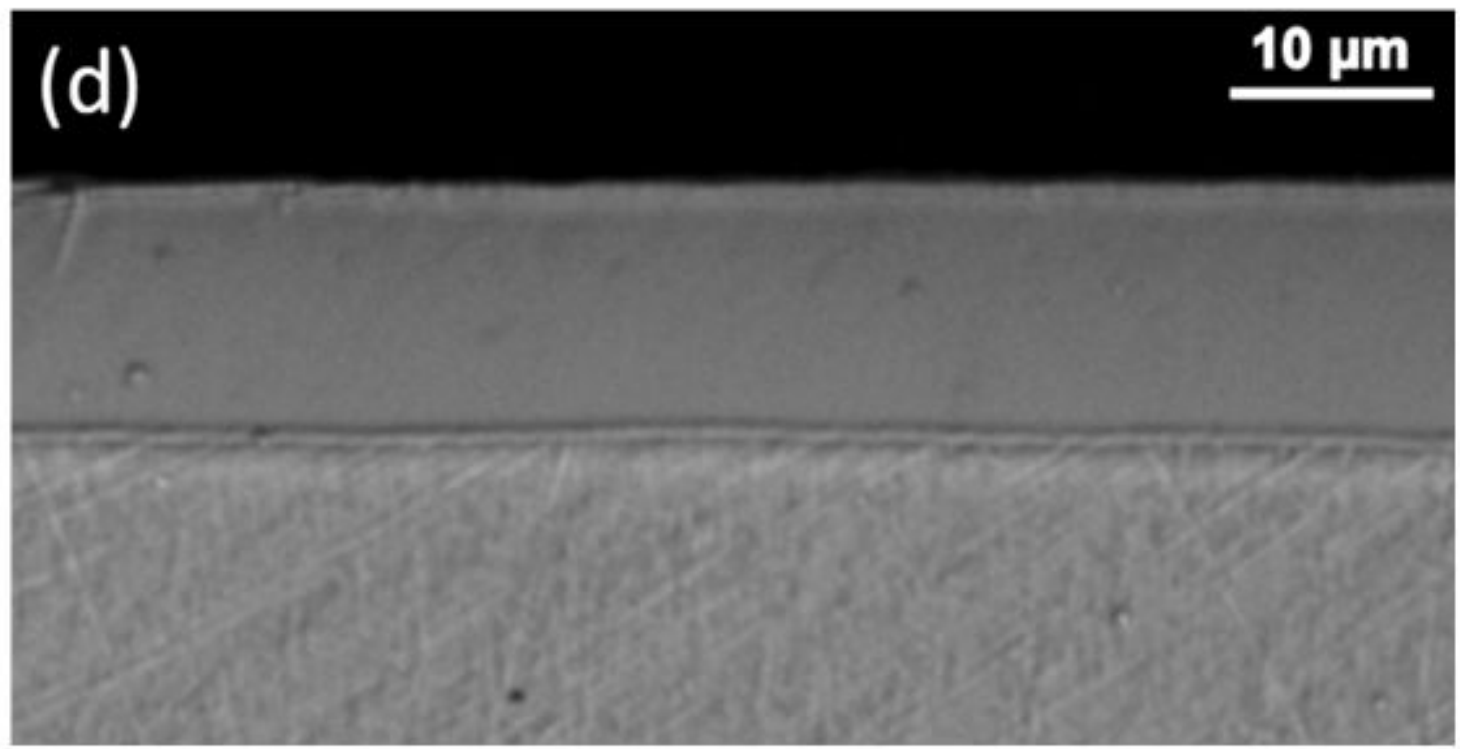

Figure 8: micrographs of low-temperature nitrided steels: AISI 316 HTSN (a) and deformed $\varepsilon=0.42$ (b), AISI 304L HTSN (c) and deformed $\varepsilon=0.45$ (d), EN $1.4369 \operatorname{HTSN}(e)$ and deformed $\varepsilon=0.50(\mathrm{f})$. 


\section{Figure $8 \mathrm{e}$}

(e)

10 pm

Figure 8: micrographs of low-temperature nitrided steels: AISI 316 HTSN (a) and deformed $\varepsilon=0.42$ (b), AISI 304L HTSN (c) and deformed $\varepsilon=0.45$ (d), EN $1.4369 \operatorname{HTSN}(e)$ and deformed $\varepsilon=0.50$ (f). 


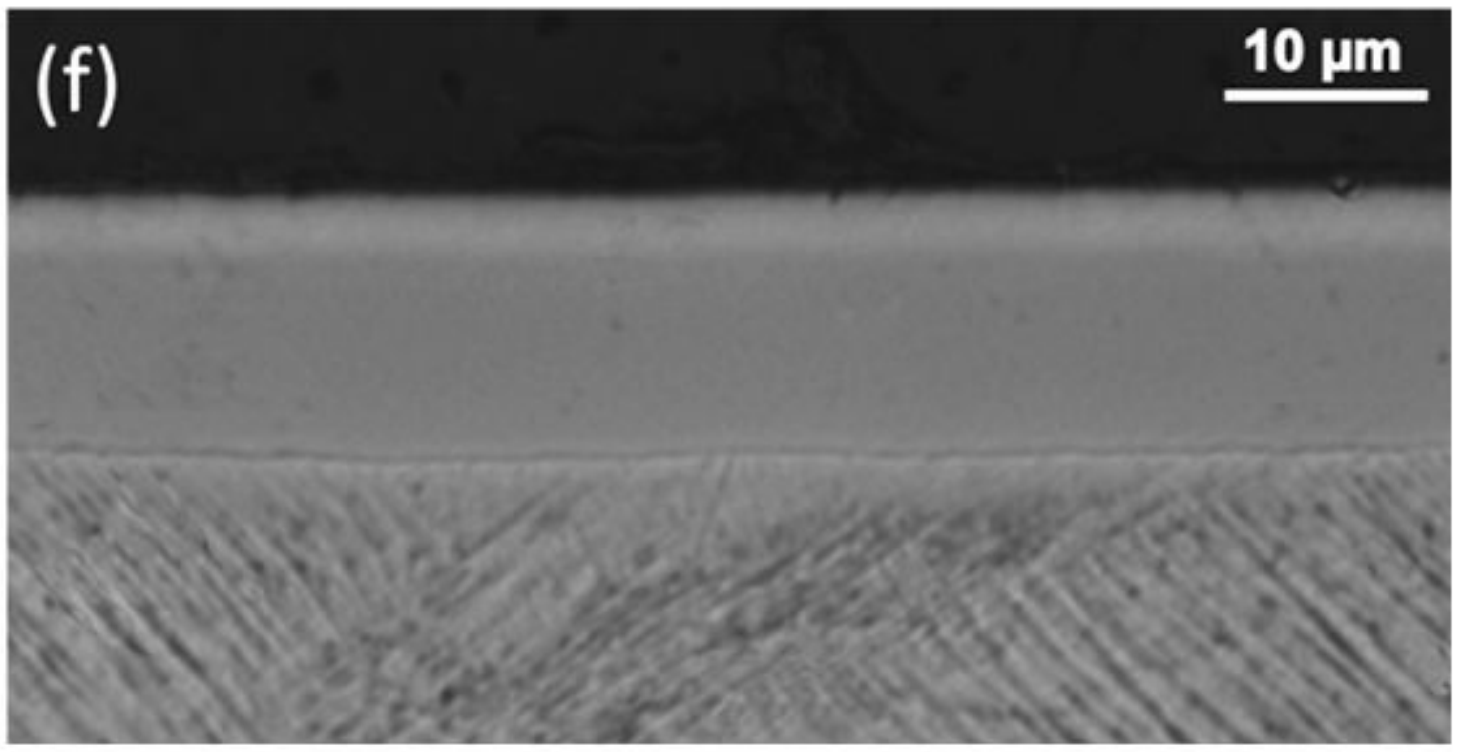

Figure 8: micrographs of low-temperature nitrided steels: AISI 316 HTSN (a) and deformed $\varepsilon=0.42$ (b), AISI 304L HTSN (c) and deformed $\varepsilon=0.45$ (d), EN $1.4369 \operatorname{HTSN}(e)$ and deformed $\varepsilon=0.50(\mathrm{f})$. 


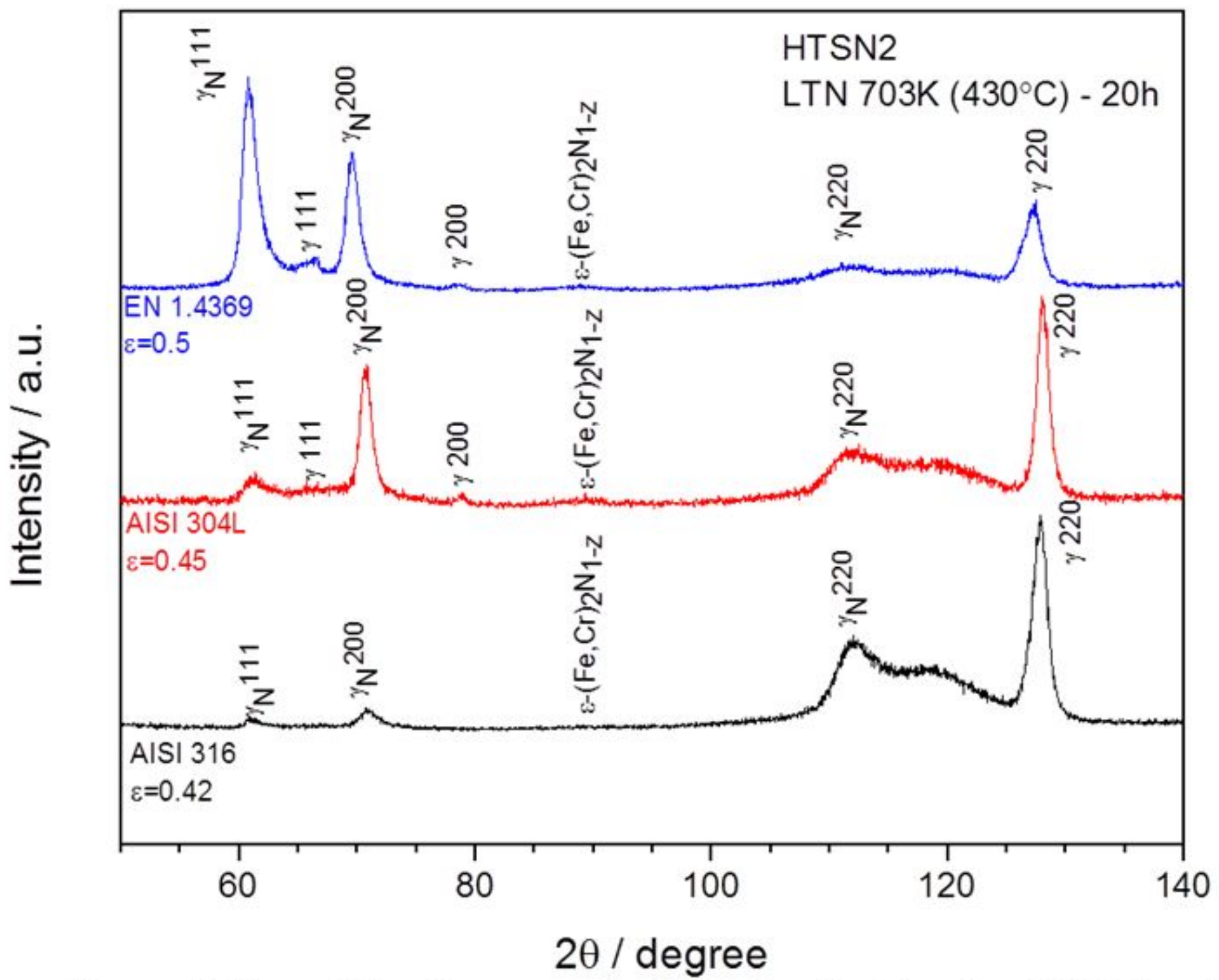

Figure 9: X-ray diffractograms of nitrided materials after HTSN2 and plastic deformation at the highest equivalent strain achieved for the three alloys (Nitriding condition $\left.703 \mathrm{~K}\left(430^{\circ} \mathrm{C}\right), 20 \mathrm{~h}\right)$. 

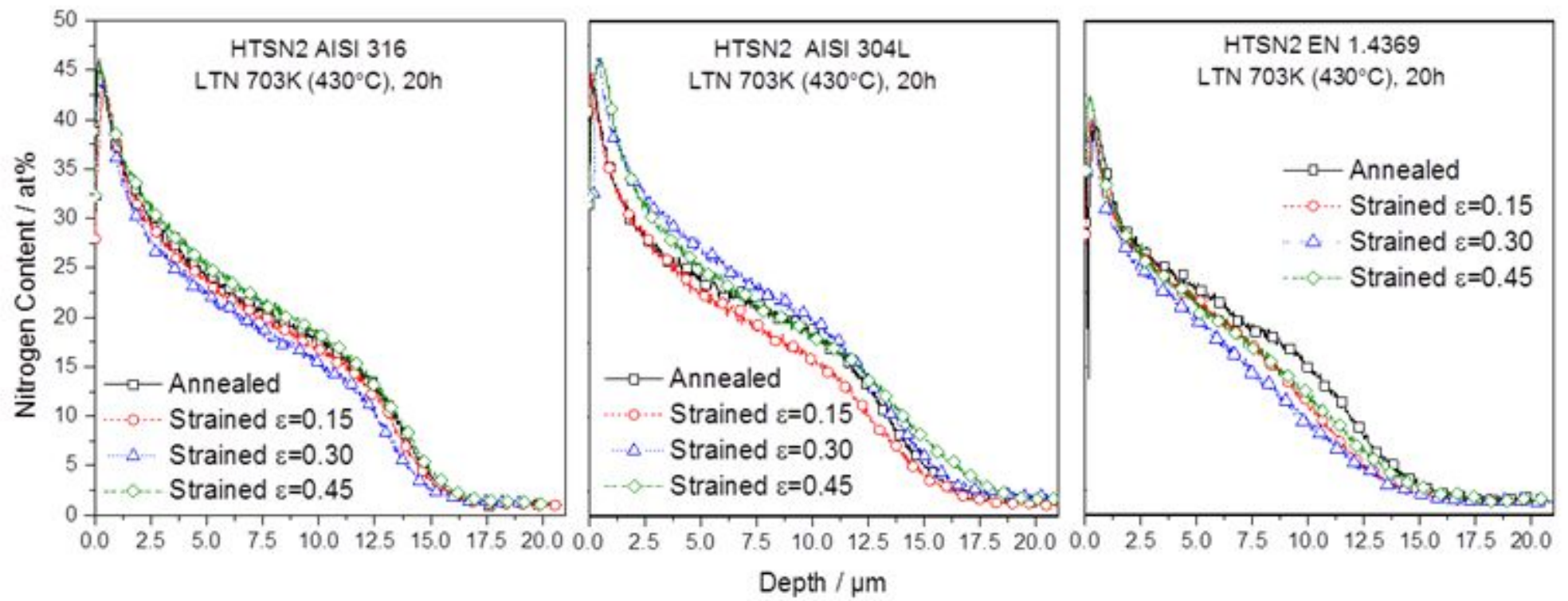

(d)

(e)

(f)
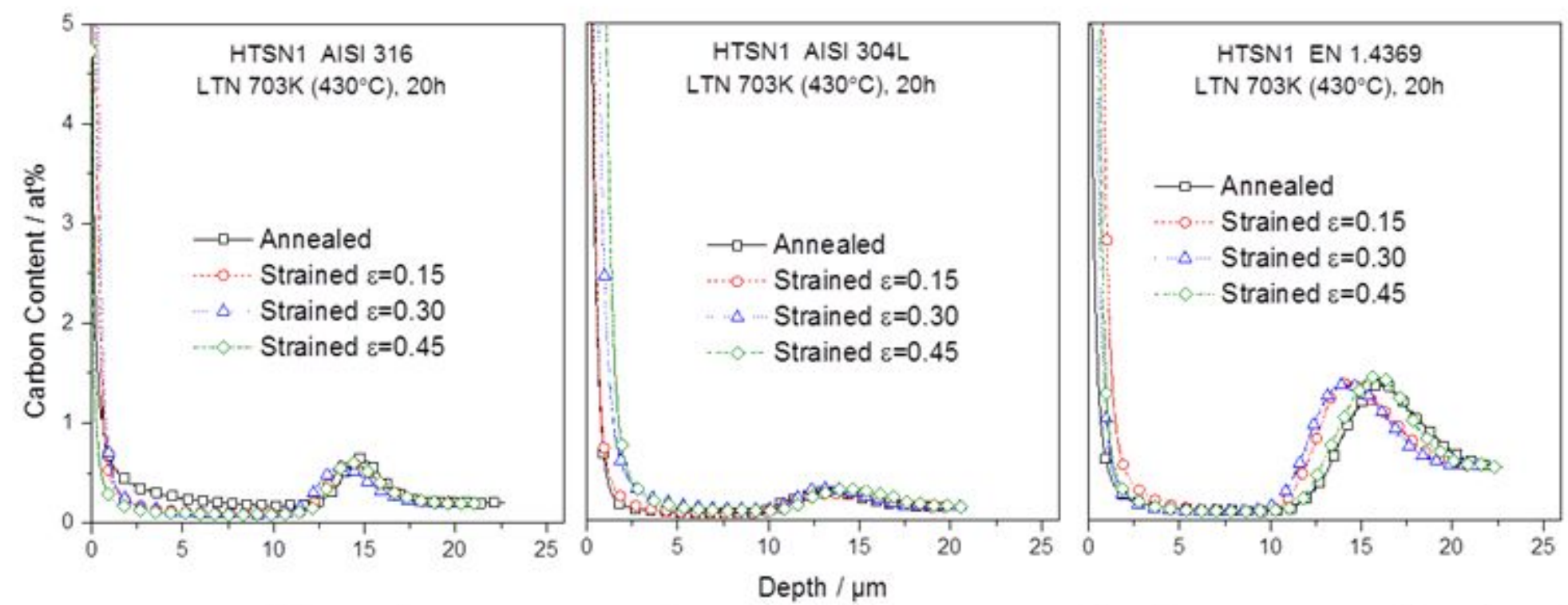

Figure 10: GD-OES profiles of nitrogen and carbon for AISI $316(a, d)$, AISI 304L (b,e) and EN $1.4369(\mathrm{c}, \mathrm{f})$ after HTSN2, deformation and low-temperature nitriding $\left(703 \mathrm{~K}\left(430^{\circ} \mathrm{C}\right), 20 \mathrm{~h}\right)$. 


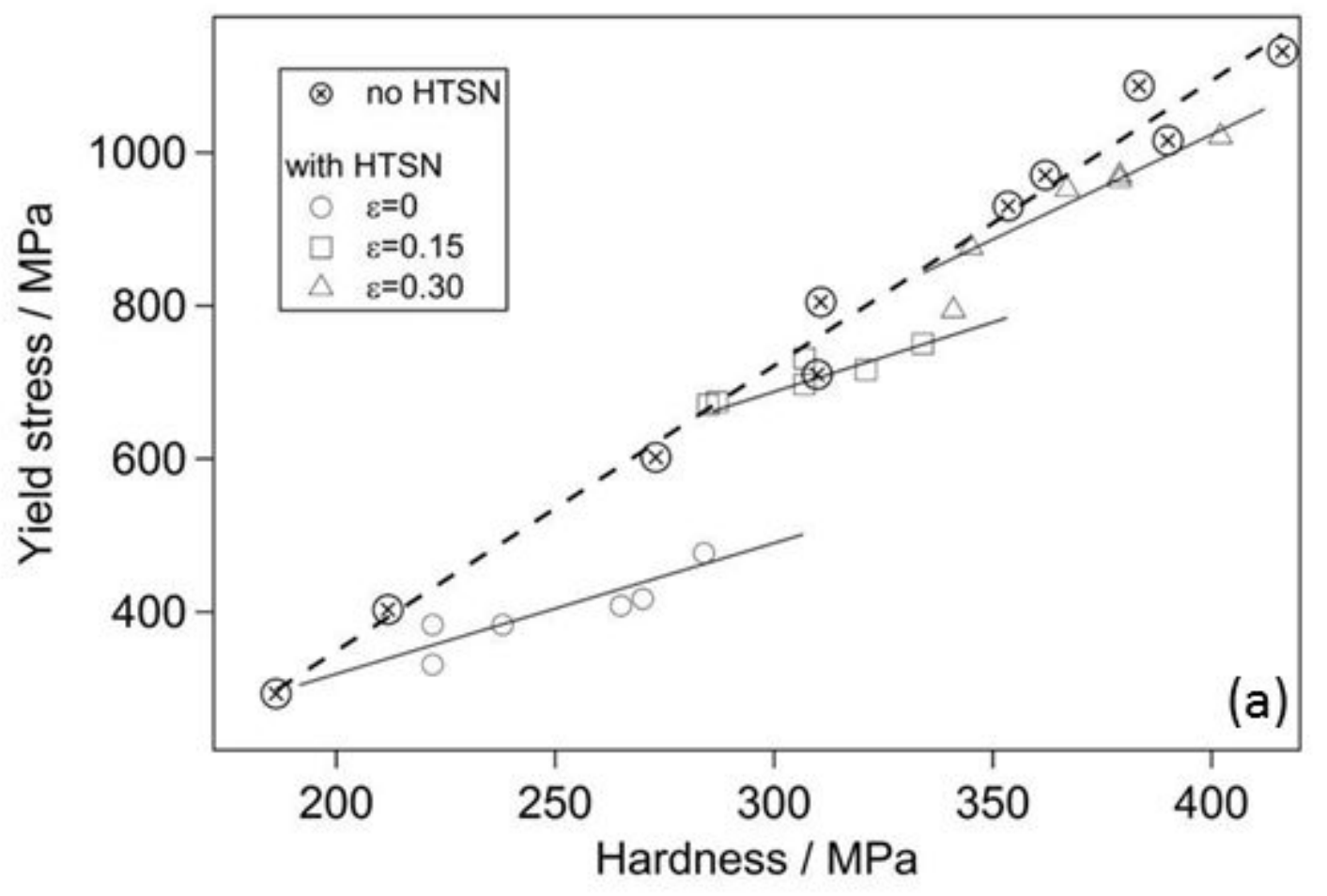

Figure 11: Yield stress for three levels of equivalent strain as a function of the hardness $\mathrm{HV}_{2.0 \mathrm{~N}}$. The dashed line indicates the straining/hardening that can be achieved by plastic deformation. (a) experimental yield stress for each equivalent strain, (b) stress corresponding to a strain $9 \%$ larger than the equivalent strain level. 


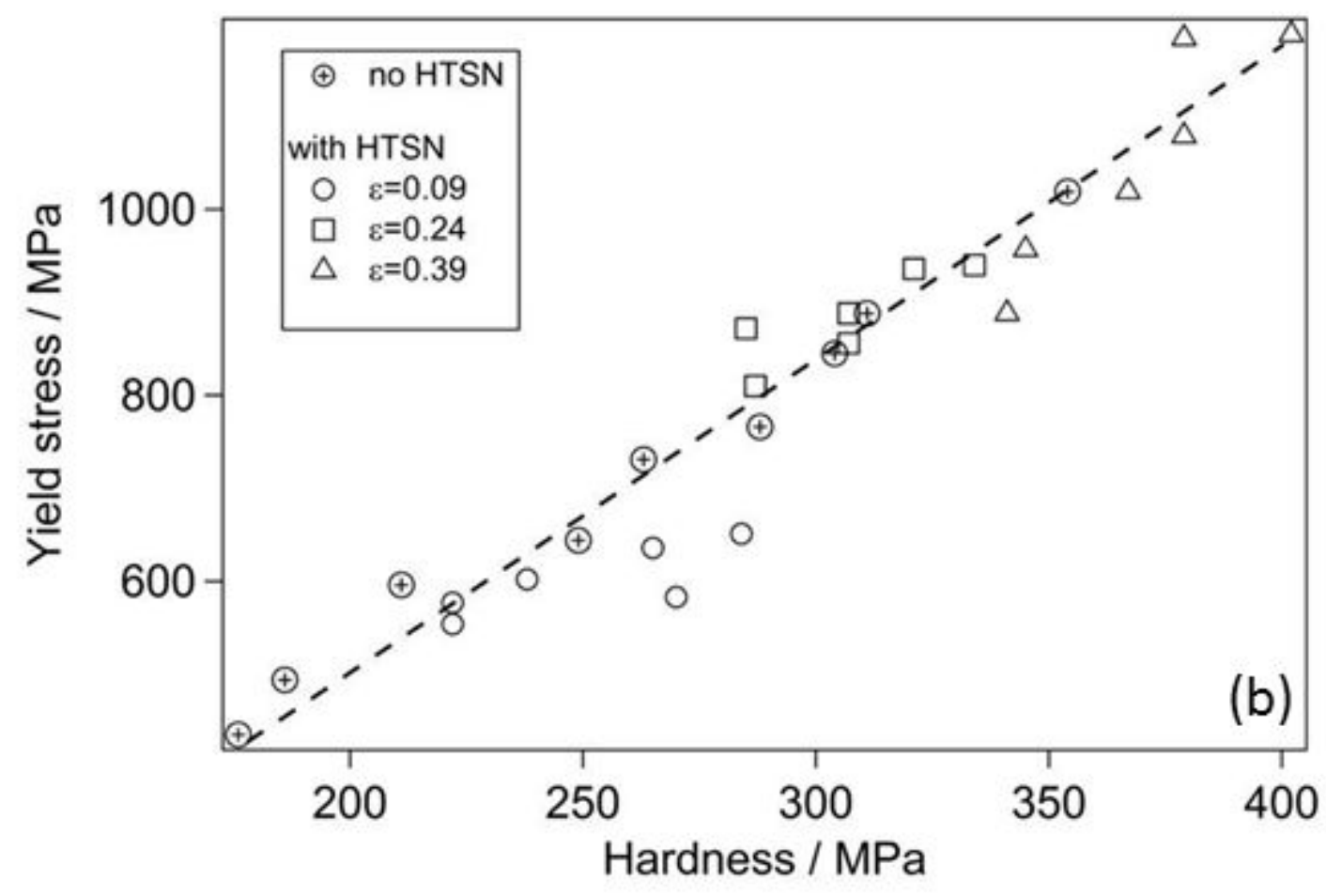

Figure 11: Yield stress for three levels of equivalent strain as a function of the hardness $\mathrm{HV}_{2.0 \mathrm{~N}}$. The dashed line indicates the straining/hardening that can be achieved by plastic deformation. a) experimental yield stress for each equivalent strain, b) stress corresponding to a strain $9 \%$ larger than the equivalent strain level. 